\title{
Hedging with Two Futures Contracts: Simplicity Pays
}

Van Thi Tuong Nguyen, Katelijne A.E. Carbonez, Piet Sercu

DEPARTMENT OF ACCOUNTANCY, FINANCE AND INSURANCE (AFI) 


\title{
Hedging with Two Futures Contracts: Simplicity Pays*
}

\author{
Van Thi Tuong Nguyen ${ }^{\dagger}$ \\ Katelijne A.E. Carbonez $z^{\ddagger}$ \\ Piet Sercu ${ }^{\S}$
}

Tuesday $2^{\text {nd }}$ March, 2010

\begin{abstract}
We propose to use two futures contracts in hedging an agricultural commodity commitment to solve either the standard delta hedge or the roll-over issue. Most current literature on dual-hedge strategies is based on a structured model to reduce roll-over risk and is somehow difficult to apply for agricultural futures contracts. Instead, we propose to apply a regression based model and a naive rules of thumb for dual-hedges which are applicable for agricultural commodities.

The naive dual strategy stems from the fact that in a large sample of agricultural commodities, De Ville, Dhaene and Sercu (2008) find that GARCH-based hedges do not perform as well as OLs-based ones and that we can avoid estimation error with such a simple rule. Our expectations-based naive hedge ratios are driven from two conditions: omitting exposure to spot price and eliminating the expected basis effects on the portfolio values. It is also noisy, though, so the first-pass hedge ratios need to be smoothed. (We use a modified version of Gelper et al. (2007) for the purpose.) We find that, generally, (i) rebalancing helps; (ii) the two-contract hedging rules do better than the one-contract counterparts, even for standard delta hedges without rolling-over; (iii) simplicity pays: within the two-contract group, the expectations-based naive rule systematically beats the others in most cases and GARCH performs worse than OLS for either one-contract or twocontract hedges; and (v) smoothing procedure does help even for regression models. These conclusions are based on the tests on unconditional variance (Diebold and Mariano (1995)) and those on conditional risk (Giacomini and White (2006)).
\end{abstract}

JEL classification: G11, Q11, Q14

Key words: hedging strategy, hedge ratio, convenience yield

\footnotetext{
${ }^{*}$ We gratefully acknowledge financial support from FWO and ICM, and help with the data from the USDA. We also thank Klyuev Vladimir, Eric de Bodt and Michel Levasseur for useful comments, and other participants at the All China Economics International Conference (Hongkong), workshop at K.U. Leuven and the joint financial economics seminar ESC/Universite de Lille. All errors are the authors'.

${ }^{\dagger}$ FWO PhD Fellow at Leuven School of Business and Economics, K.U.Leuven, Naamsestraat 69, B-3000 Leuven; +32 163264 62; thituongvan.nguyen@econ.kuleuven.be

${ }^{\ddagger}$ ICM PhD Fellow at Leuven School of Business and Economics, K.U.Leuven, Naamsestraat 69, B-3000 Leuven; +32 163266 59; Katelijne.Carbonez@econ.kuleuven.be

${ }^{\S}$ Leuven School of Business and Economics, K.U.Leuven, Naamsestraat 69, B-3000 Leuven; +32 16326756 ; Piet.Sercu@econ.kuleuven.be
} 


\section{Introduction}

This paper considers the problem of hedging a commodity commitment using two futures contracts rather than one. We find that two-contract hedges are useful not just to manage roll-over risk, an area where they are well established, but also for standard delta hedges, especially when hedging is done dynamically. In addition, we find that simple regressions tend to outclass sophisticated ones, and that a two-contract variant of the naive one-to-one hedge ratio typically does even better.

In general, hedgers use two futures contracts, either because they face a combination of two risks for each of which a separate hedge is available, or because the hedge instrument is driven by two sources of risk which the hedger wants to recombine in different proportions. An example where the hedger faces a combination of two separately hedgeable risks would be the scenario where, say, a European buyer of vegetable oils hedges the risk of the Euro price of soy oil via a СBOT contract for the dollar price risk, and a dollar/euro forward or futures for the exchange risk. A familiar example of the second type, where the complication stems from the presence of two risks in the hedge instruments, is the roll-over hedge. This occurs when the horizon of the hedger's commitment is longer than the lives of the available contracts or perhaps of the sufficiently liquid ones. The hedger then needs to roll-over the hedge when the shorter futures contracts mature and later-dated futures contracts start trading. In the familiar analysis, the roll-over introduces basis risk: we face uncertainty about the size of the difference between the final futures price of the expiring contract (which is close to the then prevailing spot price) and the futures price of the new contract at the time of the roll-over. However, if the basis of the new contract is driven by substantially the same factors as the basis of currently traded contracts, and if the relationship is known, we can approximately replicate the new contract already before it is traded. If, for example, the hedger wants a twelve-month contract but he/she can work with six- and nine-month versions only, he/she tries to best replicate the twelve-month contract using the available material.

Standard delta hedges, as defined in most of the literature, differ from roll-over hedges in that the exposed position expires before rather than after the hedge instruments. The usual approach is to adopt a static hedge and adjust the hedge ratio, for instance on the basis of regression analysis. But also here a potential role is present for a two-contract strategy. If the ideal contract has a life of, for instance, two months while only three- and six-month instruments are traded, one can still try to optimally replicate the desired hedge using the 
available contracts, exactly as in the case of a roll-over problem. This paper deals with both these applications, i.e. roll-over and delta hedge problems.

Setting up a hedging policy involves more, though, than choosing between single- or dualcontract hedges. At least equally crucial is the rule for setting the hedge ratio(s) and the related issue of static versus dynamic hedging. Most applications go for either a structured model, a regression model or a naive rule of thumb. A structured model is usually set in continuous time and prescribes a detailed dynamic hedging policy. Naive rules avoid both analysis and statistics. Examples are hedging one ton spot by one ton forward. Like regression hedges, the naive rules are often static. We discuss them in more detail below.

In a structured model we specify the equations of motion, we then derive a corresponding hedge policy and apply it dynamically, like delta hedging of options. On paper, i.e. within the model's assumptions, the hedge works perfectly. With a regression model, on the other hand, we go for a static minimum-variance hedge ratio, commonly ascribed to Ederington (1979) but already known to Stein (1961) and Johnson (1960). In a one-contract hedge, such a hedge ratio is given by the conditional slope coefficient of a regression of $\Delta S$, by the future change in the spot price to which one is exposed on $\Delta f$, and by the change in the futures price that is being used as the hedge. If the second moments of spot and futures price changes are constant, this hedge ratio is best estimated by OLS on past data. Many refinements to this strategy have been proposed, including dynamic hedging strategies (which exploit either the time-varying volatility of the spot and futures returns-GARCH; see Baillie and Myers, 1991), or error-correction in the spot-futures basis-ECM (Kroner and Sultan, 1993), or the randomcoefficients regression model (Bera, Garcia and Roh, 1997). With a naive rule of thumb, lastly, we hedge one to one (bushel by bushel), or hedge one unit of currency $i$ by $h$ units of currency $j$ and set $h$ equal to the current cross exchange rate. Results from performance races are mixed. Some studies conclude that among the single-contract hedges the naive rule performs worse than regression, while in the latter class GARCH, possibly combined with an error-correctionmodel, seems to do best (see the above references). However, in a large sample of agricultural commodities, De Ville and Dhaene (2008) find that GARCH-based hedges do not perform as well as OLS-based ones, while in Sercu and $\mathrm{Wu}(2000)$ the rules of thumb beat regression hedges for exchange risks, especially for high- $R^{2}$ currency pairs.

In contrast to the wide literature on one-contract hedges, prior research on two-contract 
strategy in commodity markets $^{1}$ mostly focus on structural models set up for the specific purpose of reducing the roll-over risk (Gibson and Schwartz, 1990; Brennan, 1991; Brennan and Crew, 1995; Schwartz, 1997; Neuberger, 1999; Veld-Merkoulova and De Roon, 2003; and Bülher, Korn and Schöbel, 2004). Even though these strategies often do quite well in oil or metals markets, they may be more difficult to apply in the case of agricultural commodities. For example, agricultural contracts have fixed delivery dates rather than the fixed lives we see in currency, oil or metal forward markets. Also, there are strong jumps in the basis at the time of the harvest. For these reasons it is hard to see how the basis could be a simple process of the type assumed in the roll-over literature. In this paper we accordingly propose to use two-contract hedging strategies for agricultural commodities and focus on regression models and naive rules of thumb, which are easily applied to agricultural futures contracts. For tworegressor minimum-variance models, we use OLS and GARCH to related changes in spot price $(\Delta S)$ to changes in first-nearest futures price $\left(\Delta f_{1}\right)$ and second-nearest futures price $\left(\Delta f_{2}\right)$. Below, we refer to them as the OLS-2 and GARCH-2 policies. The naive rules we consider set the sum of the two hedge ratios quite mechanically, close to one-bushel-for-one-bushel in fact, and then decide on the mix of the two futures contracts, on the basis of either time to maturity or projected basis. We refer to these hedge policies as the TTM- and expectations-based naive rules, respectively. Our other contending rules are single-regressor OLS and GARCH, and the one-for-one rule of thumb for a one-contract hedge.

On the whole, our empirical results show that all hedges work rather well, regardless of the number of hedges and the rule for fixing the ratio(s). Still, dual hedges do work better than single ones, and simplicity pays: among dual hedges, the naive rule works best, before oLs and then GARCH. So, a naive rule of thumb does well even though it is almost surely biased, relative to a regression-based strategy. Sercu and Uppal (1995), for instance, show that the cross-rate rule in currency cross-hedges emerges if the regression coefficient between the two currencies is assumed to be unity, which is generally an overestimation (Sercu, 2009). But while this bias is avoided by regression, any statistics-based hedge ratio will always involve an estimation error. In addition, these particular regressions use bad data. There is bid-ask bounce in the futures data, for instance, and there are synchronization problems. In addition, for agricultural futures contracts, the time to maturity and basis in the historic data base change all the time, while one ideally should use data with the time to maturity and initial basis of the hedge problem

\footnotetext{
${ }^{1}$ For fixed-income markets, two-factor models are far more dominant.
} 
at hand, for instance, changes over two months in the spot price and in a futures price with an initial basis of 15 cents and initial life of three months. The standard regressions ignore these subtleties, and treat data with all sorts of lives and basis levels as equally relevant. These, obviously, are the handicaps that make regression approaches do worse than the naive rules of thumb, despite the latter's bias. Also simplicity may help explain why real-world traders often prefer naive rules over theoretically better grounded hedging policies. Among its strong sides we also note that the naive rule easily handles the jump in basis around harvest and the everchanging lives of contracts, and avoids reliance on a particular time-series model. Besides the bias it has one more weakness, though: the proposed hedge ratio is noisy, and smoothing over time is necessary to make it work well. For even-handedness, we then test whether smoothing would help in regression too, to which, to our mild surprise, the answer is yes. That is, in rolling regressions with fourteen years of weekly data, the noise is still so bad that smoothing helps.

To sum up, the paper has the following research questions: (1) does a dual-hedge work better than a single-hedge for agricultural commodities? (2) does rebalancing help? (3) does a more complicated model based on GARCH outperform a simpler one (OLS)? (4) do the naive dual rules of thumb outperform two-contract regression model (OLS-2)? (5) does smoothing of first-pass hedge ratios generally help to improve the hedge performance? We add a last one: (6) does the dual-hedge still work better when transaction costs are considered?

To answer these questions and to evaluate performance of competing strategies, we adopt the following test set up: we hedge a long-term agricultural commodity commitment using short-maturity futures contracts (roll-over issue) or a short-term agricultural commodity commitment using long-maturity futures contracts (delta hedge issue) for-1, 2, 4, 6, 8, 10 and 12-week hedging horizons-for corn, soybeans and wheat. We apply both static hedges and dynamic versions with weekly rebalancing. Our testing period is from $1 / 1989$ to $8 / 2007$. The out-of-sample part runs from 13/12/2002 to 1/8/2007. We use daily futures price data for corn, wheat and soybeans for the March, May, July, September and December contracts (corn and wheat) and for the January, March, May, July, August, September and November contracts (soybeans). The futures price is the daily settlement price reported at The Chicago Board of Trade (Свот). Data for inventory and storage cost are from СвОт (provided by the University of Illinois). We use prices of the nearest-to-maturity futures contract instead of cash prices (spot prices) in calculating convenience yield and in testing our models. The reason is that cash prices differ dramatically even 28 miles away, while the nearest futures and the deferred futures 
are based on the same location and so avoid location issues. We do not include the maturity month of the contract into the analysis because the delivery date is not fixed precisely. ${ }^{2}$ For the interest rate, we use the 3-month LIBOR rates. We use non-overlapping data to avoid bias in the hedging effectiveness. To compare the hedging performance of alternative strategies, we consider both the variance reduction for the portfolio and the utility gains after transaction cost. Comparisons of competing hedges are made unconditionally as well as conditionally, applying Diebold and Mariano (1995) and Giacomini and White (2006), respectively, to test the significance of the difference in the implied conditional variances and the expected utility gains of two strategies.

We conclude this introduction with more information on the results which we group according to our six research questions stated earlier. These show, first, that in terms of variance reduction, even for delta hedges without rolling over the two-contract strategies perform better than the one-contract counterparts: OLS-2 wins OLS in 16 cases (out of 18), GARCH-2 beats GARCH in 17 cases and the expectations-based naive rule outperforms the traditional naive version in 14 cases. Second, also for delta hedges, rebalancing does help to reduce the variance. Third, we find that only in 5 out of 18 cases (and all of these for the same commodity) the GARCH-based strategy beats the OLs-based counterpart for either the single- or dual-hedge variant. This result not only confirms our simplicity-pays rule, but also contradicts some published studies-which, it must be added, typically used much shorter time series. Fourth, among the dual-hedge strategies, the expectations-based naive rule is the leader: it ends up first in 11 cases, while OLs, the runner-up, wins just 4 times. In addition, all of these 4 occur for corn. OLS does not systematically perform well for soybeans and wheat. Fifth, in most cases the smoothing procedure helps to result in better performance even for moving regressions with more than fourteen years of data and weekly rebalancing. Only for soybeans the gain is observed just once. The fact that regressions with 750 degrees of freedom are still quite sensitive to small shifts in the sample testifies to the severity of estimation-error problems. Finally, when transaction costs are considered, the expectations-based naive rules result in the highest utility gains in 11 cases, including all 6 for corn and 5 out of 6 for wheat. The lone exception is soybeans for which the one-contract hedges perform significantly better than the dual-hedges. A closer look at the sample characteristics reveals that for soybeans the basis

\footnotetext{
${ }^{2}$ As long as the model is linear in TTM, errors in $T-t$ equally affect all observations, whether TTM is large or small. But in the non-linear models that follow, errors in $T-t$ disproportionably affect observations near the end of the contract's life. For the sake of comparability, we omit the final month everywhere.
} 
is most highly correlated with the price. Thus, basis risk is well picked up by a one-contract hedge and the remaining risk is so small that the benefit from further reducing is usually wiped out by transaction costs. Bringing up significance, lastly, it is worth noting that nearly all the statistically clear differences for either variance reduction or utility gains (if any) are in favor of the expectations-based naive rule. There is only one case (one-week horizon, corn, in the case of variance reduction) of a significant result against that naive rule.

The remainder of this paper is structured as follows. In Section 1, we summarize the current literature on dual-hedge with roll-over hedging purpose. We describe the way to derive the naive dual hedge ratios in Section 2. In Section 3, the evaluation method for the hedge performance is presented. Section 4 is about the empirical results. Section 5 concludes.

\section{The literature on roll-over (dual) hedging}

As mentioned in the introduction part, most of the current literature on two-contract hedges focuses on reducing roll-over risk. Research on this topic, like Gibson and Schwartz (1990), Brennan (1991), Brennan and Crew (1995), Schwartz (1997), Neuberger (1999), Veld-Merkoulova and De Roon (2003) and Bülher, Korn and Schöbel (2004)-all focusing on crude oil, orange juice and lumber-demonstrates that the problem of hedging error, when rolling over the shortdated futures contracts, can be reduced by holding, at every moment, positions in two futures contracts.

To model the term structure of commodity prices, Gibson and Schwartz (1990) and Brennan (1991) assume two factors, the spot price and the convenience yield that follow a joint diffusion process. By imposing the usual no-arbitrage condition, they obtain a partial differential equation which all contingent claims must satisfy. Provided that there are two futures contracts at each moment, any contingent claim can be valued and hedged perfectly. This approach is powerful in terms of creating a consistent framework for pricing and hedging all contingent claims. However, it has certain drawbacks if the aim is to apply it in agricultural markets. One is the assumption that all futures are priced with regard to each other via just two factors. While a one-factor convenience-yield process is perhaps not a bad approximation for minerals and metals, this is less likely to apply for agricultural commodities where the futures price also depends on whether the contract matures before or after the harvest time and where, accordingly, two distinct sources of risk are active, like demand and the size of the next harvest. 
Veld-Merkoulova and De Roon (2003) use a one-factor term-structure model of the convenience yields and futures contracts for two different maturities to construct a hedging strategy. They study the market for oil forwards, which, like currency forwards, have fixed lives (e.g. always 30 or 60 days, regardless of when the trade is initiated) rather than fixed delivery dates (e.g. the third Wednesday of March). Given that this approach also requires that a new contract with identical time-to-expiration is listed periodically, it cannot directly be applied to agricultural commodity markets.

Neuberger (1999) proposes to solve the rollover problem by assuming that the price of a newly listed long-dated futures contract is a linear combination of the prices of the contemporaneous shorter-dated contracts. This approach is close to our naive rule and yields good results in hedging long-term exposure in the crude oil market. However, again, this approach cannot directly be applied to agricultural commodities because it also requires fixed time-to-maturity regressors (i.e. each month the newly listed futures contracts must have the same standard time to expiration): agricultural futures markets offer fewer contracts and new contracts are not opened at equally spaced dates.

Therefore, even if all of these models work well, they are rather difficult to apply for agricultural commodity futures contracts. So, one of the motivations for our research is to find a dual-hedge rule that can be applied for agricultural commodities.

\section{Specification of the dual hedges}

As usual, we assume that at time $t$, a hedger has perfect knowledge about the size and the maturity either of his/her future inventory holdings or of his/her future commitment in a certain commodity. Our purpose is to find a good strategy to hedge against the possible changes in the market value of that commodity investment or commitment. More specifically, we want to determine the amount of each futures contracts per unit of the given spot position to minimize the uncertainty about the hedged flow.

Current time is denoted as $t$, and the futures contract expires at $T ; C_{t, T}$ refers to the current cost of storage in dollar terms per period; $r_{t, T}$ is the one-period risk-free rate of return in the financial markets; $S_{t}$ and $f_{t, T}$ denote spot and futures prices, respectively, and $Y_{t, T}$ denotes the convenience yield of holding inventory from $t$ to $T$. Then, futures prices are related to spot prices through the costs of storage, time value, and the dollar convenience yield:

$$
f_{t, T}=S_{t} \cdot\left[1+r_{t, T} \cdot(T-t)\right]+C_{t, T} \cdot(T-t)-Y_{t, T}
$$




\subsection{Rule 1 for naive policies: matching spot-price exposure}

We assume, as is usual in this literature, that the hedger has a fixed position in the underlying commodity. The hedger wants to use two futures contracts to hedge his/her spot position. Denote $h_{1, t}$ and $h_{2, t}$ as the hedge ratios of the nearest-to-maturity and second-nearest-tomaturity futures contracts, maturing at time $T_{1}$ and $T_{2}\left(T_{2}>T_{1}\right)$ respectively. Suppose the hedging horizon is $m$ periods. The optimal hedge ratios depend on whether there is rebalancing or not.

If the hedge horizon is shorter than the maturities of two futures $\left(t+m<T_{1}<T_{2}\right)$, it is possible (but not necessarily optimal) to keep the hedged portfolio from time $t$ until the end of horizon $t+m$ without rebalancing. The portfolio value at the end of horizon $\left(V_{p, t+m}\right)$ is shown below, followed by the expression for its change. ${ }^{3}$ We use $\Delta x_{t+m}$ to denote $x_{t+m}-x_{t}$ :

$$
\begin{aligned}
\Delta V_{p, t+m} & =\left(S_{t+m}-S_{t}\right)-\sum_{i=1}^{2} h_{i, t} \cdot\left(f_{t+m, T_{i}}-f_{t, T_{i}}\right), \\
& =: \Delta S_{t+m}-\sum_{i=1}^{2} h_{i, t} \cdot \Delta f_{t+m, T_{i}} .
\end{aligned}
$$

From Equation (1), assuming that the interest rate and the storage cost have not changed, the futures price change from $t$ to $t+1$ is given by:

$$
\begin{aligned}
\Delta f_{t+1, T}= & {\left[S_{t+1} \cdot\left[1+r_{t, T} \cdot(T-t-1)\right]+C_{t, T} \cdot(T-t-1)-Y_{t+1, T}\right] } \\
& -\left[S_{t} \cdot\left[1+r_{t, T} \cdot(T-t)\right]+C_{t, T} \cdot(T-t)-Y_{t, T}\right] \\
= & \Delta S_{t+1} \cdot\left[1+r_{t, T} \cdot(T-t-1)\right]-S_{t} \cdot r_{t, T}-C_{t, T}-Y_{t+1, T}+Y_{t, T} .
\end{aligned}
$$

Below, we substitute this into (2), use notation $r_{t}$ as the one period risk-free rate of return

\footnotetext{
${ }^{3}$ In keeping with the literature, all cash flows from marking to market are treated as if they were concentrated at the end. This will not systematically affect the cashflow as long as the daily price changes are independent of the interest rates, which for commodities is not an unreasonable assumption.
} 
instead of $r_{t, T_{i}}$, regroup, and finally compress the notation:

$$
\begin{aligned}
\Delta V_{p, t+m}= & \Delta S_{t+m}-\sum_{i=1}^{2} h_{i, t} \cdot\left\{\Delta S_{t+m} \cdot\left[1+r_{t} \cdot\left(T_{i}-t-m\right)\right]-S_{t} \cdot r_{t} \cdot m-C_{t, T_{i}} \cdot m-\Delta Y_{t+m, T}\right\} \\
= & \Delta S_{t+m}\left[1-\sum_{i=1}^{2} h_{i, t} \cdot\left[1+r_{t} \cdot\left(T_{i}-t-m\right)\right]\right] \\
& \quad+\sum_{i=1}^{2} h_{i, t} \cdot\left[\Delta Y_{t+m, T_{i}}+S_{t} \cdot r_{t} \cdot m+C_{t, T_{i}} \cdot m\right] \\
= & \Delta S_{t+m} \cdot A_{t}+\sum_{i=1}^{2} h_{i, t} \cdot\left[\Delta Y_{t+m, T_{i}}-B_{t, T_{i}}\right]
\end{aligned}
$$

with $A_{t}:=\left[1-\sum_{i=1}^{2} h_{i, t} \cdot\left(1+r_{t} \cdot\left(T_{i}-t-m\right)\right)\right]$ and $B_{t, T_{i}}:=-S_{t} \cdot r_{t} \cdot m-C_{t, T_{i}} \cdot m$.

Our first heuristic solution for a naive dual hedge is to first and foremost eliminate all exposure to the prime source of variability, the spot price. Thus, the hedge ratios must satisfy:

$$
A_{t}:=1-\sum_{i=1}^{2} h_{i, t} \cdot\left(1+r_{t} \cdot\left(T_{i}-t-m\right)\right)=0 .
$$

This differs somewhat from a bushel-for-bushel naive hedge, which would have said that one bushel should be hedged by, in total, one bushel sold in the futures markets. The correction here takes into account the remaining life of each of the futures contracts at the time the hedges are liquidated. Numerically, however, this comes close to a one-for-one rule for the sum of the two hedge ratios. The above relation is also the secret weapon of the rule: it gives us a hard equation for the sum of the hedge ratios. While the constraint is likely to be biased (because, unlike a regression-based strategy, it ignores covariances with the convenience yield), it requires no estimation and is, therefore, free of estimation error.

To get a unique solution for the two $h$ s separately, we need a second condition. We could minimize the variance of the second term in Equation (4) subject to (5), but that would bring us too close to regression-like solutions that we want to avoid and would get us positive values for both $h \mathrm{~s}$, which is not what OLS or GARCH tell us we should get. Instead, we have two alternative suggestions. Our first and main suggestion is to eliminate the expected basis effects. Note that basis is the difference between spot and futures prices: $f_{t, T}-S_{t}$. Therefore, with the assumption that interest rate and storage cost have not changed, Equation (1) implies that factors which derive expected basis and expected convenience yield are the same. As a result, eliminating expected convenience yield effects leads to the same result as eliminating expected basis effects. The second solution, which is simpler, is to match the duration of two futures contracts with the duration of the hedge. Below, we discuss each of them in more 
detail.

\subsection{Rule 2a for naive policies: eliminating expected convenience yield ef- fects}

To eliminate expected yield effects, we set the expectation of the second term in (4) equal to zero. We refer to this rule as expectations-based naive rule. Disadvantages of this rule are: (i) it requires a model for the expected convenience yields at time $t+m$; and (ii) it is not a risk-minimizing approach. However, it has the advantage of tending to neutralize convenience yields on average-not as good as eliminating ex post convenience at the horizon date $T$, but still a step in the right direction. As $Y_{t, T_{2}}>Y_{t, T_{1}}$ (unless possibly if there is no harvest during the life of two contracts), this rule tends to produce values for $h_{1}$ above unity, and values for $h_{2}$ below zero, which is what one would expect. Given that, by assumption, the horizon $m$ is shorter than $T_{1}$ and $T_{2},{ }^{4}$ the hedge-ratio pattern plausibly means that the combination of the two contracts seeks to extrapolate the contracts' properties towards a horizon shorter than $T_{1}$, like $T$. The soundness of this intuition is confirmed by average OLS- and GARCH-based hedge ratios, which do follow that pattern. Therefore, we impose:

$$
\sum_{i=1}^{2} h_{i, t} \cdot \mathrm{E}_{t}\left(\Delta Y_{t+m, T_{i}}-B_{t, T_{i}}\right)=0 .
$$

Solving the two constraints, we get:

$$
\begin{aligned}
h_{1, t} & =\frac{\mathrm{E}_{t}\left(\Delta Y_{t+m, T_{2}}\right)-B_{t, T_{2}}}{\left[\mathrm{E}_{t}\left(\Delta Y_{t+m, T_{2}}\right)-B_{t, T_{2}}\right] \cdot\left[1+r_{t} \cdot\left(T_{1}-t-m\right)\right]-\left[\mathrm{E}_{t}\left(\Delta Y_{t+m, T_{1}}\right)-B_{t, T_{1}}\right] \cdot\left[1+r_{t} \cdot\left(T_{2}-t-m\right)\right]}, \\
h_{2, t} & =\frac{-\left[\mathrm{E}_{t}\left(\Delta Y_{t+m, T_{1}}\right)-B_{t, T_{1}}\right]}{\left[\mathrm{E}_{t}\left(\Delta Y_{t+m, T_{2}}\right)-B_{t, T_{2}}\right] \cdot\left[1+r_{t} \cdot\left(T_{1}-t-m\right)\right]-\left[\mathrm{E}_{t}\left(\Delta Y_{t+m, T_{1}}\right)-B_{t, T_{1}}\right] \cdot\left[1+r_{t} \cdot\left(T_{2}-t-m\right)\right]} .
\end{aligned}
$$

The above considers a static delta hedge, never rebalanced. Now, suppose we want to rebalance the portfolio every period during the hedging horizon $m$, each period lasting $k$ year where $k \ll 1$ and $t+k<T_{1}, T_{2}$. In this case, the total portfolio value $t$ to $t+m$ is equal to the summed portfolio value realized in every subperiod. ${ }^{5}$

$$
\Delta V_{p, t+m}=\sum_{j=1}^{m / k}\left(S_{t+k j}-S_{t+k(j-1)}\right)-\sum_{j=1}^{m / k} \sum_{i=1}^{2} h_{i, t+k(j-1)} \cdot\left(f_{t+k j, T_{i}}-f_{t+k(j-1), T_{i}}\right)
$$

\footnotetext{
${ }^{4}$ This is a fortiori the case with rebalancing, when the interim horizon shrinks to one week.

${ }^{5}$ This again ignores time value of the marking-to-market cash flows, as standard in this literature.
} 
To reduce the total variability, for every period we act in the same way as for the static hedge, except that the local horizon now is $k$ rather than $m$. Such myopic period-by-period hedging is inspired by the near-absence of autocorrelation in the spot prices over short horizons and the relatively low variance of the changes in the convenience yields. Thus, for $j=1$ to $m / k$,

$$
\begin{aligned}
& h_{1, t+k(j-1)}=\frac{\left[\mathrm{E}_{t}\left(\Delta Y_{t+k j, T_{2}}\right)-B_{t+k(j-1), T_{2}}\right]}{\left[\begin{array}{c}
{\left[\mathrm{E}_{t}\left(\Delta Y_{t+k j, T_{2}}\right)-B_{t+k(j-1), T_{2}}\right] \cdot\left[1+r_{t+k(j-1)} \cdot\left(T_{1}-t-k j\right)\right]} \\
-\left[\mathrm{E}_{t}\left(\Delta Y_{t+k j, T_{1}}\right)-B_{t+k(j-1), T_{1}}\right] \cdot\left[1+r_{t+k(j-1)} \cdot\left(T_{2}-t-k j\right)\right]
\end{array}\right]}, \\
& h_{2, t+k(j-1)}=\frac{-\left[\mathrm{E}_{t}\left(\Delta Y_{t+k j, T_{1}}\right)-B_{t+k(j-1), T_{1}}\right]}{\left[\begin{array}{c}
{\left[\mathrm{E}_{t}\left(\Delta Y_{t+k j, T_{2}}\right)-B_{t+k(j-1), T_{2}}\right] \cdot\left[1+r_{t+k(j-1)} \cdot\left(T_{1}-t-k j\right)\right]} \\
-\left[\mathrm{E}_{t}\left(\Delta Y_{t+k j, T_{1}}\right)-B_{t+k(j-1), T_{1}}\right] \cdot\left[1+r_{t+k(j-1)} \cdot\left(T_{2}-t-k j\right)\right]
\end{array}\right]} .
\end{aligned}
$$

\subsection{Rule $2 \mathrm{~b}$ for naive policies: matching duration}

As the expectations-based naive rule requires a model for expected futures yields, it is not strictly a simple rule and obviously introduces forecast errors. Such a problem can be avoided if yields are postulated to be proportional with the contract's life: $\mathrm{E}_{t}\left(Y_{t, T}\right)=a_{t, T}+b_{t, T}(T-t)$. The condition for eliminating the expected convenience yield at the horizon then simplifies to:

$$
\left\{\begin{array}{l}
H=h_{1, t-1} \cdot\left(T_{1}-t\right)+h_{2, t-1} \cdot\left(T_{2}-t\right), \\
h_{1, t-1}+h_{2, t-1}=1,
\end{array}\right.
$$

with $H$ the hedging horizon and $\left(T_{i}-t\right)$ the time to maturity of futures contracts. The second condition of the system means that the method is a real naive dual hedging rule without correcting for the remaining life of contracts. Solving the above system, we get:

$$
\left\{\begin{array}{l}
h_{1, t-1}=\frac{\left(T_{2}-t\right)-H}{\left(T_{2}-t\right)-\left(T_{1}-t\right)}, \\
h_{2, t-1}=1-h_{1, t-1}
\end{array}\right.
$$

We refer to this rule as TTM-based naive rule, to differentiate it from the more general main solution, the expectations-based naive hedge. This TTM-based naive rule has one advantage over the more general expectations-based version: no estimation error is involved, and therefore no smoothing procedure needs to be applied. However, its weak side is the assumption of, at any moment, an affine relation between convenience yields and time to maturities. Therefore, the final verdict is an empirical matter. 


\subsection{The expectation-based rule: forecasting the convenience yield}

In order to forecast the convenience yield, we follow Carbonez, Nguyen and Sercu (2008) (CNS). Recall that they show that convenience yield of agricultural commodities like corn, soybeans and wheat is well approximated by the product of time to maturity and a function of current scarcity, $\phi(x, S, \ldots)$, involving e.g. inventories $x$ and/or the spot price $S$. In addition, if there is a harvest during the contract's life, a new term is introduced that involves a product of a similar function of scarcity, $\psi(x, S, \ldots)$ and the timespan from harvest to delivery:

$$
Y\left(x, S, t ; T, T_{h}\right)=\phi\left(x_{t}, S_{t-1}, \ldots\right) \cdot(T-t)+\psi\left(x_{t}, S_{t-1}, \ldots\right) \cdot \max \left(T-T_{h}, 0\right) .
$$

Regarding the arguments of the current marginal convenience yield function $\phi()$, CNS experiment with the current inventory in Chicago, the spot price, or both of them. This multiplicative model does far better than standard additive ones. Using the multiplicative model as the yardstick, CNS also find that, for the period 1986-2007, current scarcity is better captured, in-sample, by the spot price than by inventory. In this study, in order to see which proxy is the best measure of scarcity in out-of-sample forecasting of convenience yields, we again try each of the three models, named after their key variable: the 'Inventory', 'Price', and 'Combined' model.

In their estimation of the inventory model, CNS use storage data that are synchronized with the yields, but we use inventory at time $t-1$ instead, because time $t$ inventory is not yet known at time $t-1$, when the convenience yield at time $t$ is being forecast. Autocorrelation for weekly inventory data at lag one is very high (around 0.92 for all commodities even after filtering out a Hodrick-Presscott trend). This suggests that little is lost when we use inventory at time $t-1$ as a proxy for inventory at $t .^{6}$

Table 12 summarizes the estimation results for the 'Combined', 'Inventory' and 'Price' models. This estimation is with weekly data and for the initial-estimation period, 1989-2002.

\subsection{Smoothing the hedge ratios}

Errors in forecasting arise even with the best model, so the calculated hedge ratios suffer from outliers or errors. To solve the outlier problem and smooth the calculated hedge ratios, we

\footnotetext{
${ }^{6}$ As an alternative we have also predicted inventory by an $\operatorname{AR}(2)$ model. We stop at lag two because the coefficient is insignificant for lag three. However, the results are nearly the same as when we use inventory at time $t-1$.
} 
apply the Gelper, Fried and Croux (2007) robust exponential-smoothing method. Under this approach a smoothed series of hedge ratio is computed using the following recursive scheme: ${ }^{7}$

$$
\widetilde{h}_{t}=\gamma h_{t}^{*}+(1-\gamma) \widetilde{h}_{t-1}
$$

where $\widetilde{h}_{t}$ is the smoothed hedge ratio at time $t, h_{t}^{*}$ is the time $t$ 'cleaned' value of the raw hedge ratio $h_{t}$ and $\gamma$ is the smoothing parameter taking values between zero and unity. The smaller this smoothing parameter, the less weight is applied to the most recent observations and thus the smoother the series will be. The cleaning boils down to pre-shrinking the outliers, and using these instead of the raw numbers as inputs for the smoothing algorithm. This cleaned value is obtained as:

$$
h_{t}^{*}=\vartheta\left(\frac{h_{t}-\widehat{h}_{t \mid t-1}}{\widehat{\sigma}_{t}}\right) \widehat{\sigma}_{t}+\widehat{h}_{t \mid t-1},
$$

where the $\vartheta$-function is applied to standardized one-step-ahead forecast errors. $\widehat{h}_{t \mid t-1}$, the one-step ahead forecast made at time $t-1$, is the smoothed valued at $t-1: \widehat{h}_{t \mid t-1}=\widetilde{h}_{t-1}$. The scale of these forecast errors is estimated by $\widehat{\sigma}_{t}$. The $\vartheta$-function is the Huber $\vartheta$-function, a truncation to reduce the influence of outlying observations:

$$
\vartheta(z)= \begin{cases}\mathrm{z} & \text { if }|z|<k, \\ \operatorname{sign}(\mathrm{z}) k & \text { otherwise }\end{cases}
$$

The cleaning performed by the $\vartheta$-function replaces unusually high or low values by a more likely value. Specifically, if the difference between the observed hedge ratios $h_{t}$ and its predicted value at $t-1$ is small, the cleaned value $h_{t}^{*}$ simply equals the observed value $h_{t}$, but if the difference is too large, the observation is considered an outlier and gets replaced by a boundary value that depends on $k$. A common choice of $k$ is 2, implicitly referring to a normal distribution of one-step-ahead forecast errors $r_{t}=h_{t}-\widehat{h}_{t \mid t-1}$. In addition, the estimated scale $\widehat{\sigma}_{t}$ is calculated by the following update equation to allow for (slowly) a varying scale instead of a constant scale:

$$
\widehat{\sigma}_{t}^{2}=\gamma_{\sigma} \xi\left(\frac{r_{t}}{\widehat{\sigma}_{t-1}}\right) \widehat{\sigma}_{t-1}^{2}+\left(1-\gamma_{\sigma}\right) \widehat{\sigma}_{t-1}^{2}
$$

This time, a bounded loss-function $\xi$ is used rather than a truncation:

$$
\xi(z)= \begin{cases}c_{k}\left(1-\left(1-(z / k)^{2}\right)^{3}\right) & \text { if }|z|<k \\ c_{k} & \text { otherwise }\end{cases}
$$

\footnotetext{
${ }^{7}$ Our hedge ratios have neither seasonality nor long-term trend, otherwise a more complicated version would be in order.
} 
where $c_{k}$ is a constant to achieve consistency with the scale parameter which has a normal error distribution. We have $c_{k}=2.52$ for $k=2$.

One problem with Equation (13) is that it does not consider the local trend or momentum in the series. It always predicts a return to a long-run mean, while we also want to take into account whether the observed value at $t$ is higher or lower than the observed value at $t-1$. That is, we want the smoothed series to follow the local trend in the observed series, so that when the observed value at $t$ increases, the smoothed value at $t$ must be higher than the smoothed value at $t-1$ and via versa. To do this, we modify the recursive scheme of Equation (13) as follows:

$$
\widetilde{h}_{t}=\operatorname{sign}\left(u_{t}\right) \gamma h_{t}^{*}+\left[1-\operatorname{sign}\left(u_{t}\right) \gamma\right] \widetilde{h}_{t-1},
$$

where $u_{t}=\left(h_{t}-h_{t-1}\right)\left(h_{t}^{*}-\widetilde{h}_{t-1}\right)$.

The starting value for $\widehat{\sigma}$ is obtained by the Median Absolute Deviation (MAD) in the startup period of the first 10 observations:

$$
\widehat{\sigma}_{t}=\operatorname{MAD}_{1 \leq s \leq t}\left(r_{s}\right)=\operatorname{med}_{1 \leq s \leq t}\left|r_{s}-\operatorname{med}_{1 \leq s \leq t} r_{s}\right|
$$

\subsection{Minimum-variance hedges}

We apply standard regression hedges too: OLS and OLS-2, and GARCH and GARCH-2. For the first pair we regress the following equation with OLS:

$$
P_{S, t}=\alpha-\beta P_{f_{T_{1}}, t}-\gamma P_{f_{T_{2}}, t}+\epsilon
$$

with hedge ratios defined as: $h_{1}=\beta$ and $h_{2}=\gamma ; P_{S, t}=\frac{\Delta S_{t}}{S_{t-1}} ; P_{f_{T_{i}}, t}=\frac{\Delta f_{t, T_{i}}}{f_{t-1, T_{i}}} ;$ and $V_{p, t+1}=$ $\Delta S_{t+1}-\sum_{1}^{2} h_{i} \Delta f_{t+1, T_{i}}$. For CCC-GARCH-2, we estimate CCC-GARCH(1,1) for the following system:

$$
\left\{\begin{aligned}
P_{S, t} & =\alpha_{1}+\beta_{1} P_{S, t-1}+\gamma_{1} P_{f_{T_{1}}, t-1}+\epsilon_{1} \\
P_{f_{T_{1}}, t} & =\alpha_{2}+\beta_{2} P_{S, t-1}+\gamma_{2} P_{f_{T_{1}}, t-1}+\epsilon_{2} \\
P_{f_{T_{2}}, t} & =\alpha_{3}+\beta_{2} P_{S, t-1}+\gamma_{3} P_{f_{T_{2}}, t-1}+\epsilon_{3}
\end{aligned}\right.
$$

with hedge ratios defined as the two-regressor slope coefficients:

$$
h_{i, t}=\frac{\operatorname{var}_{t}\left(f_{t+1, T_{j}}\right) \operatorname{cov}_{t}\left(P_{S, t+1}, P_{f_{T_{i}}, t+1}\right)-\operatorname{cov}_{t}\left(P_{f_{T_{i}}, t+1}, P_{f_{T_{j}}, t+1}\right) \operatorname{cov}_{t}\left(P_{S, t+1}, P_{f_{T_{j}}, t+1}\right) \mid I_{t}}{\operatorname{var}_{t}\left(P_{f_{T_{i}}, t+1}\right) \operatorname{var}_{t}\left(P_{f_{T_{j}}, t+1}\right)-\operatorname{cov}_{t}\left(P_{f_{T_{i}}, t+1}, P_{f_{T_{j}}, t+1}\right)^{2} \mid I_{t}}
$$

with $i=1, j=2$ and $i=2, j=1$. The GARCH regressions are of the constant conditional correlation (CCC) type. Too often, the more general BEKK version fails to converge.

We should note that also in the statistics-based hedges the role of the second contract in the two-contract rule seems to cut down the impact of convenience yield in the hedge: we see 
a weight exceeding unity for the nearest-dated contract, and a negative weight for he furtherdated one, the one with the higher convenience yield. One consequence is that the two-contract rule will be less useful, either when the convenience yields of two futures contracts are highly correlated and the difference between them is just a tiny or when they have high correlations with the spot price. In such cases, either the convenience yield risk is very small or most of risks are well picked up by a simple one-regressor hedgee already, and thus the role of the second contract or the role of eliminating basis risk is less useful. This may be even more so when the benefit from reducing basis risk must be traded off against the high transaction cost for two-contract hedges.

\section{Evaluating the conditional hedging effectiveness}

For each hedging strategy, we can compute, for every hedge period $(t, t+m)$, a realized cash flow. We then compute squared cash flows. There is, of course, substantial variation over time in the spot and the closely related futures price, inducing a good dose of heteroscedasticity into the time series of hedged cash flows. Accordingly, we rescale each realized cash flow by dividing it by the spot price at $t .^{8}$ Therefore, the variance of the scaled cash flow is:

$$
V S C:=\frac{\sum_{t=t_{1}}^{T_{N}-m}\left(\frac{\Delta V_{p, t+m}}{S_{t}}-\frac{\overline{\Delta V_{p, .+m}}}{S_{t}}\right)^{2}}{T_{\text {out }}},
$$

with $T_{\text {out }}$ the number of observations in the testing period for each hedging horizon.

To judge the relative performance of two competing hedging strategies that have a riskminimization objective, normally one compares the percentage reduction between the variances of the hedged and the unhedged portfolio returns. The strategy that provides the highest relative variance reduction is then deemed to be the best one. However, this method suffers from two major problems. First, being an unconditional measure, it is not adequate when the objective is to evaluate a dynamic strategy resulting from the minimization of the conditional portfolio return variance, as done, for instance, under GARCH. If variances change, a statistical test that assumed constant variance is suboptimal. Secondly, it is also not sufficient to simply check the unconditional performance because a good unconditional relative hedging performance may still have a poor conditional relative hedging performance at particular moments. An unconditional criterion would make sense only if, once the hedger selects

\footnotetext{
${ }^{8}$ Within a given hedge period with rebalancing, the cashflows are accumulated without rescaling: dollar price changes are additive, returns are not.
} 
a particular method, like OLS, he/she is committed to using it for ever. Now, ols may do well on average, but there must still be days when, conditionally, GARCH is expected to do better because the conditional variance of its hedge happens to be lower on that particular day. Accordingly, a conditional test has, as its null, that at any moment the conditional variances of two contending strategies are equal, which, if not rejected, would mean that there is no statistically convincing ground for switching.

In this paper, besides comparing the unconditional variances of portfolio returns from alternative hedging strategies, we apply the Diebold and Mariano (1995) (DM) and Giacomini and White (2006) (GW) statistical test to unconditionally and conditionally compare the conditional portfolio return variances implied by competing hedging strategies. The DM test is still an unconditional test, but it does take into account changing variances. In that sense, the test is complementary to the standard one and more in line with the idea of changing uncertainty. In addition, the test goes beyond a simple comparison of variances in that it allows inference too. To measure conditional hedging effectiveness, the conditional portfolio return variance obtained from each strategy is compared. Denote by $c v_{t}\left(t^{1}\right)$ and $c v_{t}\left(t^{2}\right)$ the squared demeaned out-of-sample portfolio return obtained by hedging strategy $t^{1}$ and $t^{2}$ respectively. Andersen and Bollerslev (1998) and Diebold and Lopez (1996), among others, note that these squared demeaned portfolio returns are unbiased estimates of the true conditional variance. Let the difference in the squared demeaned returns be $\mathrm{d} v_{t} \equiv c v_{t}\left(t^{1}\right)-c v_{t}\left(t^{2}\right)$. The DM method is an unconditional test of the null hypothesis of equal conditional hedging effectiveness:

$$
H_{0, d m}: E_{t}\left[\mathrm{~d} v_{t}\right]=0
$$

We define $T_{\text {out }}:=$ the number of observations used out-of-sample; $\overline{\mathrm{d} v}:=T_{\text {out }}^{-1} \sum_{t=T_{\text {in }}+1}^{T} \mathrm{~d} v_{t}$; $\widehat{L R V}\left(\mathrm{~d} v_{t}\right):=$ the estimate of long run variance of $\mathrm{d} v_{t}$; and:

$$
d m:=\frac{\sqrt{T_{\text {out }}} \cdot \overline{\mathrm{d} v}}{\sqrt{\widehat{L R V}\left(\mathrm{~d} v_{t}\right)}},
$$

which is a standard t-test on a mean (of $\mathrm{d} v$, here). Diebold and Mariano (1995) show that $d m \stackrel{\mathrm{d} v}{\rightarrow} N(0,1)$. In an application, the DM statistic can be computed as the $t$-statistic in a regression of $\mathrm{d} v_{t}$ on a constant with the Newey-West standard error. Note that the sign of $\overline{\mathrm{d} v}$ indicates the direction of rejection of the two-sided DM test. If in our test we observe, for instance, $\overline{\mathrm{d} v}<0$, this implies that $c v\left(t^{1}\right)<c v\left(t^{2}\right)$, i.e. that strategy $t^{1}$ does better than $t^{2}$ and vice versa.

Giacomini and White (2006) propose a conditional test. They construct a test of $H_{0, z}$ 
against the two-sided alternative:

$$
H_{1, z}: E\left[Z_{t}\right]^{\prime} E\left[Z_{t}\right]>0
$$

The GW test statistic can be written as:

$$
g w_{z}=T_{\text {out }} R^{2}
$$

where $R^{2}$ is the uncentered square multiple correlation coefficient for the artificial regression $\iota=Z \theta+\epsilon$. Define $Z \equiv\left(\mathrm{d} v_{T_{\text {in }}+1} z_{T_{\text {in }}}^{\prime} \ldots \mathrm{d} v_{T} z_{T-1}^{\prime}\right)^{\prime}$, a $T_{\text {out }} \times q$ matrix and $\iota$, a $T_{\text {out }} \times 1$ vector of ones. Under $H_{0, z}, g w_{z} \stackrel{\mathrm{d} v}{\rightarrow} \chi_{(q)}^{2}$. We choose the test function $z_{t-1}$ as follows:

$$
z_{t-1} \equiv\left(1, S_{t-1}, Y_{t-1, T_{1}}, \mathrm{~d} v_{t-1}, f_{t-1, T_{1}}, S_{t-1} f_{t-1, T_{1}}\right)^{\prime}
$$

The GW is large-sample, so we cannot apply the GW test for horizons beyond one week because of insufficient observations.

\section{Data and results}

\subsection{Test and parameters set-up}

\section{Test set up}

The data sources were described in the introduction. As inventory data used to be released once a week only, the price data are sampled for the same days as those for which the inventory is known. Our total weekly sample, from 2/1/1989 to 1/8/2007, contains 969 observations for each commodity. Simple returns are always calculated from the same contract. This means that, if at time $t+1$ the spliced-together series is jumping from a shorter contract to a longer contract, the futures return at this time is computed from two prices for the longer contract, while the one at time $t$ is computed from the last two prices for the shorter contract.

As mentioned and motivated in the introduction, we use the nearest-to-maturity futures prices to stand in for the spot prices, and thus the second-nearest-to-maturity and the thirdnearest-to-maturity series are used to test the heuristic (i.e. naive) strategy. We test the rule for hedge horizons of one, four, six, eight, ten, and twelve weeks, with either weekly rebalancing or no rebalancing. To avoid statistical issues in assessing the confidence intervals for hedging effectiveness and so on, we use non-overlapping data. We divide the sample into two subperiods: the initial estimation period and the (out-of-sample) testing period. The initial estimation period $\left(T_{i n}\right)$ is from $2 / 1 / 1989$ to $7 / 12 / 2002$-about three fourths of the sample, a 
common procedure. The out-of-sample $\left(T_{\text {out }}\right)$ testing period is from $13 / 12 / 2002$ to $1 / 8 / 2007$. With the non-overlapping method, this results in $727,175,113,83,65$, and 52 observations in the initial estimation for the one-, four-, six-, eight-, ten-, and twelve-week hedging horizons respectively. The corresponding numbers are 242, 67, 48, 39, 32, and 28 for the out-of-sample testing. As the name suggests, the initial-estimation observations are used to estimate or calculate the hedge ratio for the first hedge experiment in the test period. Then, at time $t=T_{\text {in }}+1$, we add the new observation realized at that time to the sample. We delete the first observation from the sample and we re-estimate the model to obtain the next hedge ratio, to be used at time $T_{i n}+1$. We continue repeating this process until we reach the end of the test data. With this moving window technique, the sample size for the estimation remains constant.

Relating to the GARCH based regression model, we choose the CCC-GARCH model as our representative for the GARCH class of models to avoid the alternative specifications needed to resolve the problem of a possible non-positive semi-definite conditional variance-covariance matrix of VECH-GARCH. We experimented with BEKK-GARCH but dropped it because sometimes we run into a singular-matrix problem. We apply the moving window technique for the expectation-based naive dual hedging rule, as well as for OLS and GARCH. ${ }^{9}$

We work with single-hedge strategies, viz the traditional naive one-to-one hedge, simple regression (OLS), and a CCC-GARCH strategy, and we compare them with related dual-hedge strategies: OLS-2, CCC-GARCH-2, the TTM-based naive rule, and the expectations-based naive rule. The latter comes in three versions depending on the alternative models for scarcity ('Inventory', 'Price' and 'Combined'). To level the field for the competing strategies, we also apply the smoothing procedure for regression based strategies.

\section{Starting values for the smoothing procedure}

For the expectations-based naive hedge, we first smooth the hedge ratios for the nearest-tomaturity futures contract $h_{1}$. We then use the condition $\left(1-\sum_{i=1}^{2} h_{i, t} \cdot\left(1+r_{t} \cdot\left(T_{i}-t-m\right)\right)=0\right)$ to calculate the corresponding smooth hedge ratio for the second contract. For OLS-2 and CCC-GARCH-2, we smooth for $h_{1}$ and $h_{2}$ separately, as there is no constraint on the sum of the regression-based hedge ratios.

\footnotetext{
${ }^{9}$ Estimation is obviously necessary for the regression-based hedges. But also our two-contract hedge needs (re)estimation of the Carbonez-Nguyen-Sercu regression to predict the next convenience yield.
} 
Following Gelper, Fried and Croux (2007), we set the starting value in the exponential smoothing for $h_{1}$ and $h_{2}$ of the OLS- and GARCH-based regressions at the median of the first ten observations in the testing period. For our expectations-based naive hedge, we use $h_{1}$ from the initial estimation period with OLS-2 regression as the first input for the recursive scheme in Equation (18). ${ }^{10}$ Based also on the initial estimation period, the smoothing parameter $\gamma$ equal to 0.01 is the best one. For $\gamma_{\sigma}$, Gelper, Fried and Croux (2007) set it at 0.2, but we also try 0.1 , which turns out to produce better results in our problem than 0.2. As for the smoothing procedure, we need 10 first observations as the starting period, the non-overlapping numbers of observations, to compare the hedging performance are $233,58,39,30,23$, and 19 for the one-, four-, six-, eight-, ten-, and twelve-week horizons.

\subsection{Out-of-sample results for unconditional performance}

\section{Descriptive statistics of spot prices and convenience yields}

Table 1 summarizes weekly variances and correlations of the scaled first differences of spot prices and the two convenience yields. The last column in the table compares the means of the scaled first difference of the two convenience yields. It is clear from the table that, while the spot-price variance for soybeans is somewhat below that for corn and wheat, the variances of its convenience yields are about twice those for corn and wheat. For soybeans, we also observe the highest correlation between spot price and convenience yields, that is, the (high) risk of the convenience yields can be picked up relatively well by a single hedge that also covers the spot price. Furthermore, for soybeans we also see the highest correlation between the two yields (0.934) compared with corn and wheat, and the mean difference is also smallest (only 5.7e-4\%). This means that the two hedge contracts offer essentially the same, and hedge ratios that try to exploit the small differences might pick up mostly noise. All this can harm the effectiveness of the second contract in hedging for soybeans. For wheat, the correlation between spot price and the second-contract convenience yield is not much lower than for soybeans but, at least, the difference between two yields is half as large again as that of soybeans. In short, we expect that the role for two-contract hedges is less promising for soybeans comparative to corn and wheat, especially when the transaction cost is considered.

\footnotetext{
${ }^{10}$ We also tried to use this first input for smoothing OLS- and CCC-GARCH-based hedge ratios, but the results are not as good as the median ones.
} 
Table 1: Descriptive statistics of spot prices and convenience yields for the out-of-sample

\begin{tabular}{lccccccc} 
Commodity & $\sigma_{\frac{\Delta S_{t}}{2}}^{2}$ & $\sigma_{\Delta Y_{t, T_{1}}}^{2}$ & $\sigma_{\frac{\Delta Y_{t, T_{2}}}{S_{t}}}^{2}$ & $\rho_{\frac{\Delta S_{t}}{S_{t}} \frac{\Delta Y_{t, T_{1}}}{S_{t}}}$ & $\rho_{\frac{\Delta S_{t}}{S_{t}} \frac{\Delta Y_{t, T_{2}}}{S_{t}}}$ & $\rho_{\frac{\Delta Y_{t, T_{1}}}{S_{t}} \frac{\Delta Y_{t, T_{2}}}{S_{t}}}$ & $\left(\frac{\Delta Y_{t, T_{1}}-\Delta Y_{t, T_{2}}}{S_{t}}\right)$ \\
\hline Corn & 0.00160 & 0.00006 & 0.00011 & 0.115 & 0.292 & 0.875 & 0.00076 \\
Soybeans & 0.00131 & 0.00013 & 0.00021 & 0.387 & 0.459 & 0.934 & 0.00057 \\
Wheat & 0.00167 & 0.00006 & 0.00014 & 0.283 & 0.458 & 0.791 & 0.00108 \\
\hline
\end{tabular}

Note: In this table, $\sigma_{x}^{2}$ is weekly variance of $x$, and $\rho_{x y}$ is correlation between $x$ and $y$.

\section{The benefits of smoothing}

Before we compare the hedging performance of the strategies, we want to check for the usefulness of the smoothing procedure, not only for the expectations-based naive rule but also for regression models. Table 3, at the back of this paper, provides some summary statistics for the hedge ratios that result from the expectations-based naive rules. The statistics describe the out-of-sample hedge ratios for the one-week hedging horizon. The panel on the left bears on three sets of raw hedge ratios as calculated from expected convenience yields forecasted via the 'Combined' model, the 'Inventory' model and the 'Price' model, respectively. The panel on the right refers to hedge ratios after smoothing. From the left panel, it is clear that there is a problem of excessively noisy hedge ratios. For all three models, the absolute values for minimum and maximum hedge ratios can be very high, like \pm 3000 , and they heavily influence even the time-series means of the $h$ s. When undertaking the smoothing strategy, the statistics are much more credible. While the table shows just the numbers for one-week hedges, we observe the same situation for hedge ratios with longer hedging horizons. ${ }^{11}$ This suggests that smoothing is useful for the expectations-based naive rule. Not surprisingly, with egregious slope coefficients like the original ones, the hedging performance was quite bad and often even backfired, meaning that the 'hedged' positions were more volatile than the unhedged ones. By simple truncation the results were already much more promising, though, and the current smoothing does even better.

For fairness, we extend the smoothing also to regular regressions, even though the usefulness of smoothing in the case of rolling regressions with 730 overlapping data points is far from obvious, a priori. The effect of smoothing on the distribution of hedge ratios is, of course, far less spectacular, so to show that smoothing works, we resort to an indirect and ultimately

\footnotetext{
${ }^{11}$ We can provide these results on request.
} 
Table 2: Percentage annualized variance reduction of original OLS and GARCH models and smoothed OLS and GARCH models - weekly rebalancing

\begin{tabular}{|c|c|c|c|c|c|c|c|c|c|c|c|c|}
\hline \multirow[t]{3}{*}{ Strategy } & \multicolumn{6}{|c|}{ Original hedge ratios } & \multicolumn{6}{|c|}{ Smoothed hedge ratios } \\
\hline & \multicolumn{6}{|c|}{ Hedging Horizon (in weeks) } & \multicolumn{6}{|c|}{ Hedging Horizon (in weeks) } \\
\hline & 1 & 4 & 6 & 8 & 10 & 12 & 1 & 4 & 6 & 8 & 10 & 12 \\
\hline & \multicolumn{12}{|c|}{ Panel A: Corn } \\
\hline OLS & 67.43 & 69.19 & 73.09 & 78.83 & 80.82 & 80.19 & 67.46 & 69.23 & 73.23 & 78.70 & 80.85 & 80.12 \\
\hline OLS-2 & 67.53 & 69.75 & 73.47 & 78.76 & 81.57 & 80.49 & 67.56 & 69.82 & 73.60 & 78.61 & 81.63 & 80.42 \\
\hline GARCH & 66.68 & 65.65 & 70.91 & 79.43 & 79.06 & 80.19 & 67.05 & 68.63 & 72.34 & 79.21 & 80.04 & 79.89 \\
\hline \multirow[t]{2}{*}{ GARCH-2 } & 65.66 & 65.23 & 69.31 & 76.35 & 76.01 & 76.54 & 67.05 & 69.16 & 72.58 & 79.11 & 80.82 & 80.19 \\
\hline & \multicolumn{12}{|c|}{ Panel B: Soybeans } \\
\hline OLS & 68.37 & 67.62 & 64.12 & 64.85 & 68.30 & 66.13 & 68.30 & 67.47 & 63.94 & 64.67 & 68.09 & 65.91 \\
\hline OLS-2 & 70.48 & 71.14 & 66.45 & 67.37 & 70.49 & 67.49 & 70.52 & 71.17 & 66.51 & 67.40 & 70.43 & 67.52 \\
\hline GARCH & 68.00 & 70.33 & 70.23 & 69.02 & 70.97 & 70.62 & 67.88 & 66.97 & 63.75 & 64.23 & 67.52 & 65.55 \\
\hline \multirow[t]{2}{*}{ GARCH-2 } & 70.82 & 74.95 & 73.43 & 73.09 & 74.35 & 73.14 & 69.42 & 69.55 & 65.52 & 66.10 & 68.84 & 66.71 \\
\hline & \multicolumn{12}{|c|}{ Panel C: Wheat } \\
\hline OLS & 71.48 & 79.41 & 77.85 & 81.61 & 77.92 & 82.55 & 71.71 & 79.63 & 78.17 & 81.58 & 78.09 & 82.71 \\
\hline OLS-2 & 71.44 & 79.08 & 78.64 & 83.32 & 80.20 & 84.63 & 71.74 & 79.48 & 79.07 & 83.29 & 80.25 & 84.89 \\
\hline GARCH & 70.64 & 78.07 & 77.92 & 81.48 & 76.90 & 84.22 & 71.88 & 79.38 & 78.24 & 80.39 & 77.66 & 82.32 \\
\hline GARCH-2 & 71.04 & 77.92 & 77.49 & 81.58 & 75.51 & 84.76 & 71.88 & 79.60 & 79.28 & 83.26 & 80.20 & 85.02 \\
\hline
\end{tabular}

Notes:

1. The table reports the annualized percentage variance reduction of oLs and GARCH strategies over the no hedging one from the original hedge ratios and from the smoothed hedge ratios. To annualize, we divide the standard deviation by the square root of the length of the hedging period (in years). We use 52 weeks per year to annualize portfolio return variance.

2. A number in bold indicates that the smoothed hedge ratio of the correspondent model results in higher variance reduction than the original hedge ratio.

more relevant measure: the percentage risk reductions for the original versus smoothed oLS and CCC-GARCH strategies. The results are in Table 2. For corn and wheat, the smoothed hedge ratios again result in a systematically better performance than the original hedge ratios (39 out of 48 cases). The outlier is soybeans, where only OLS- 2 seems to benefit from smoothing. As smoothing, by and large, gives better results for both the expectations-based naive rule or regression models, from now on we will use smoothed hedge ratios to compare competing strategies.

\section{Out-of-sample hedging performance with rebalancing: simple dual-hedge strate-} gies pay

Table 4 reports the measures of an unconditional relative out-of-sample hedging performance, as summarized by the percentage annualized variance reduction of alternative hedging strategies over the no hedging one. Results with weekly rebalancing are in the upper panel while results without rebalancing are in the lower panel. Our expectations-based naive strategies are reported in the last three rows of each panel, one for each of the three models for forecasting the convenience yield. To indicate the relative performance, we use boldface to indicate the best (highest) number, and we underline to indicate the second best. In this subsection we discuss 
the results with rebalancing. We expect that rebalancing helps because we can apply new hedge ratios when new information becomes available and, in the expectations-based naive hedge, because a one-week forecast is more precise than a ten-week one. Moreover, some rebalancing is actually inevitable in the case of a long-term commitment that needs rolling-over.

First, it is clear that all considered hedging strategies provide substantial (and, in fact, quite similar) variance reduction over the no hedging one, especially for long term hedging horizons. Second, comparing the traditional naive hedge rule with the TTM-based naive rule, we find that the traditional naive hedge rule is the winner in most cases. Therefore, a very simple naive dual rule does not work. This result implies that either the linearity assumption between time to maturities and convenience yields may be problematic, or that the whole setup of first matching the spot-price risk and then eliminating expected convenience-yield effects is unsound. However, our expectations-based naive rules does a much better job, as we describe below. That is, the linearity assumption is mostly to blame for the dismal performance of the simplest dual-hedge rule.

A third result, which is more central to the paper, is that the dual-hedge policies do systematically better than single-contract solutions, even for delta hedges when the hedging horizons (one or four weeks) are shorter than the maturities of hedged futures contracts. ${ }^{12}$ For clean comparisons, we contrast the single- and dual-hedge results per strategy. For simple regression, in 16 out of 18 cases (i.e. for three commodities with 6 hedging horizons each) OLS- 2 performs better than OLS, and for the more sophisticated estimates CCC-GARCH- 2 even offers higher variance reduction than $\mathrm{CCC}-\mathrm{GARCH}$ in 17 cases. Our expectations-based naive rules also beat the traditional naive rule in 14 cases.

The fourth and, to practitioners, most interesting result is that among all dual-hedge rules, the expectations-based naive rules systematically beat the others in most cases, getting ahead of OLS-2 11 times and ahead of GARCH-2 15 times. When comparing the scores with all strategies considered here, whether single- or dual-hedge, the expectations-based naive rules are only occasionally (and marginally) beaten in 7 cases (at the 1-, 4- and 6-week horizons for corn and at 1- and 4-week horizons for wheat), and in those cases the winner is not systematically the same contender. For example, OLS-2 based regression model seems to be the ex post best strategy for corn (winning in 4 out of 6 cases) but it does not perform well for soybeans and

\footnotetext{
${ }^{12}$ Recall we do not include the maturity month of futures contracts in our analysis, so maturities on the hedge side are at least 4 weeks.
} 
wheat.

So, we find regression does not really help. Moreover, if nevertheless one goes for regression, simple tools seem to do best again. In fact, our fifth finding is that, compared with OLS, GARCH wins in only 5 out of 18 cases for either single-hedge or dual-hedge. In the same simplicity-pays vein, we also find that a single-contract oLs-based hedge is beaten by the one-for-one naive rule in 11 cases. All this does not chime well with the positive conclusions about GARCH in some earlier studies (e.g. Ballie and Myers, 1991). Still, it is to be noted that they use a different data set, with much shorter series and sometimes a different GARCH specification.

Finally, among the three alternative convenience-yield models underlying the expectationsbased naive rule, we find that there is no clear winner. While 'Price' is the best model for corn, 'Inventory' does best for soybeans and wheat, and the differences between the three models are very small anyway. This will be shown more clearly in the next section, where we discuss significance tests for the differences. First, we address the issue whether rebalancing, which was applied in all the tests discussed thus far, really helps.

\section{Does rebalancing help?}

Now we consider the results without rebalancing in the lower panel of Table 4. As one would expect, for most horizons and hedging strategies, a static hedge achieves a lower variance reduction than a dynamic hedge, especially for long hedging horizons. Specifically, out of the 135 cells (commodity $\times$ strategy $\times$ horizon) that we consider, the static hedge comes out first 51 times. Rebalancing allows the hedger to update the information and use the new hedge ratios. In the case of our expectations-based naive rule, an additional advantage from rebalancing is that we only need to forecast the convenience yield one week instead of many weeks, which certainly avoids lower-precision forecasts. Therefore, it should not come as a surprise that, without rebalancing, in many cases the dual hedges do not outperform their single-hedge counterparts. In addition, there seems to be no strategy that systematically comes out ahead, providing even more of a reason for hedgers to use their option to rebalance. ${ }^{13}$

\footnotetext{
${ }^{13}$ At this first stage, we let the users rebalance every week. Later we have them weigh the cost of trading against the degree of sub-optimality of the outstanding hedge position, so that they can waive their option to rebalance at least some of the time.
} 


\section{Interim conclusions}

To sum up, comparing the variance reduction among strategies, we find that: (i) rebalancing is better than without rebalancing; (ii) the smoothing procedure does help even for regression models; (iii) dual hedges perform better than single ones, even for 'delta' problems without rolling over; (iv) the expectations-based naive rule systematically beats the other dual-hedge rules in most cases; and (v) simplicity pays. We can show, on request, that all these results remain true when we work with the original, unsmoothed hedge ratios from the regression models instead of the smoothed ones.

Still, all conclusions thus far are based on an unconditional evaluation of hedging effectiveness. What remains to be done is to add significance statements for unconditional and conditional differences in variance reduction (subsection 4.3) and transaction-cost adjusted variance (subsection 4.4). As we shall see, up to one exception, the significant differences are all in support of the expectations-based naive rule rather than the other way around, and the clearest answers are obtained when the criterion is expected utility, i.e. variance adjusted for transaction costs.

\subsection{Conditional and unconditional performance: significance tests}

As mentioned in the methodology section, due to an insufficient number of observations, we can undertake the GW test for the one-week horizon only. Still, it is reassuring to note that, at this one-week horizon, the GW and DM test results are in full agreement. Tables 6, 7 and 8 provide summaries of the results from the DM and GW tests for the out-of-sample hedging performance of alternative strategies with rebalancing. Both tests compare the variances reduction pairwise. In the table, a cell shows the result for the comparison of the model mentioned in the column header and the row header, respectively. The entry in each cell is the name of the strategy that delivers the greater reduction in the conditional variance, as gauged by the DM test. Using the $p$-values of the GW test for the one-week horizon and DM test for other horizons, we also report via the familiar asterisks whether a strategy does significantly better than the other. Finally, competing strategies are ranked according to their pairwise comparison (9 strategies in total). The best strategy (ranked 1) is the strategy that does better than all the other strategies. Next, the second best strategy (ranked 2) is the one that does better than all other remaining strategies (after taking out the ranked 1 strategy). All strategies are ranked like that. The last and worst strategy is ranked 9. 
First, and surely least unexpectedly, all hedging strategies do significantly better than the no-hedging one for all horizons and all commodities. Second, the results confirm the conclusion that we obtain from comparing the variance reduction of alternative strategies. For most of the horizons, all top spots are filled by the dual hedges. Among those, the expectationsbased naive hedges hold the top three positions in most cases. In case any competing strategy outperforms ours, it does not significantly better at any horizon, with the single exception of corn at the one-week horizon. That is, in all cases but one, where the hedge performance differs significantly from that of the expectations-based naive rule, the difference is in its favor. OLS- 2 and CCC-GARCH-2 significantly beat their one-contract counterpart in one case. In addition, we find that the traditional naive rule significantly beats CCC-GARCH in two cases. We do not find any significance the other way round in either case.

At this stage, we still conclude that dual-hedges seem to do better than single-ones, and that, given the choice for either one or two contracts in the hedge, the expectations-based naive methods seem to do better than complicated ones. We now turn to economic relevance: is any utility gained after transaction costs?

\subsection{What's left after transaction cost?}

Because the dual-hedge rule involves positions in two futures contracts, the transaction cost is likely to be higher than under a one-contract strategy, potentially even wiping out the benefit from the reduced variance. We test for this by evaluating the utility value obtained by the hedger from the dual-hedges, letting him/her decide when to revise, weighing the execution cost against the likely gain in terms of risk. To that end, we suppose that the hedger has a mean-variance utility function. That is, the hedger's criterion after taking into account the transaction cost is:

$$
U_{t-1}=\left[\mathrm{E}_{t-1}\left(R_{p, t}\right)-T C_{t-1}\right]-\frac{\lambda}{2} \cdot \operatorname{var}_{t-1}\left(R_{p, t}\right)
$$

Following Kroner and Sultan (1993), we suppose that, at time $t-1$, the hedger will only rebalance his/her portfolio when the expected utility gain at time $t$ from rebalancing at $t-1$ is higher than the loss from the transaction cost for doing it at $t-1$. In handling the expected return, we likewise follow Kroner and Sultan (1993) and take the expected portfolio return to be equal to zero, which is also in line with the design of the heuristic hedging rule. So, the hedger will not rebalance his/her portfolio at time $t-1$ (and thus maintain the same hedge ratios inherited from $t-2$ ) when the rebalancing does not improve the variance enough to 
justify the trading cost. Thus, relative risk aversion $(\lambda)$ allows us to translate risk changes into equivalent terms of expected return after percentage cost and vice versa.

Stated positively, the hedger will rebalance when:

$$
-T C_{t-1}-\frac{\lambda}{2} \cdot \operatorname{var}_{t-1}\left(R_{p, t} \mid h_{t-1}\right)>-\frac{\lambda}{2} \cdot \operatorname{var}_{t-1}\left(R_{p, t} \mid h_{t-2}\right)
$$

There are some special situations that deserve a detailed discussion. First, at the beginning of a new hedging period, we do not rebalance the portfolio since the hedge is just starting. However, we still apply the condition in Equation (29), with inherited hedge ratios from time $t-2$ equal to zero, to decide whether the hedger should hold any hedged position. ${ }^{14}$ If the above condition is not met, then for the one-contract strategies the agent does not hedge, while for the two-contract strategies, the hedger switches from a two- to a one-contract strategy. For OLS-2 and CCC-GARCH-2, the hedger obviously uses the hedge ratio from OLS and CCC-GARCH strategies when switching, while for the TTM-based naive rule the choice would be the naive hedge rule. For our the expectations-based naive strategies, the one-contract hedge ratio is calculated from Equation (5): $1-\sum_{i=1}^{2} h_{i, t} \cdot\left[1+r_{t} \cdot\left(T_{i}-t-m\right)\right]=0$ with $h_{2, t}=0$. In case the new calculated one-contract hedge ratio still does not help enough, in terms of expected risk reduction, in order to justify the expense, the hedger holds the spot position, unhedged. This way of switching from two- to one-contract strategies is also applied during the hedging period when no position is held in the long futures contract (i.e when $h_{2, t-1}=0$ ). More specifically, such situation occurs: (i) when the short-dated contract has expired and the transaction cost condition prevents the hedger from holding any position with the new long contract or (ii) when the hedger decides not to rebalance the hedged portfolio and the previous hedge ratio for the long contract is zero.

Second, consider the situation where the hedger does not rebalance the portfolio but the previous hedge ratio for the long contract is different from zero. In this case, for our expectationsbased naive rules, the hedger re-calculates the hedge ratio for a short futures contract at $t-1$ with $h_{2, t-1}=h_{2, t-2}$ based on Equation (5).

The forward-looking conditional variance at time $t$ is calculated from the CCC-GARCH model as estimated at $t-1$. Following Lien and Yang (2007), we set the transaction cost equal to 75 USD per contract ${ }^{15}$ per round trip for 5000 bushels. This is converted into a percentage

\footnotetext{
${ }^{14}$ Thus, for the one-week horizon, each week the hedger decides whether to hold a hedged position or not, not whether to rebalance the position.

${ }^{15}$ This cost includes the brokerage commission fees and bid-ask spreads.
} 
cost per bushel using the day's spot price. We test with four values for relative risk aversion $(\lambda=2,4,6$ and 8$)$. To evaluate the hedging performance of models, we compare the utility, and the best strategy is the one that generates the highest utility. We also perform the GW and DM tests to check whether the differences of the utility gains between alternative strategies are significant. In this case, $\mathrm{d} u_{t}$, defined as the utility gap $U_{t}\left(t^{1}\right)-U_{t}\left(t^{2}\right)$, replaces the variance gap $\mathrm{d} v$ in the DM test. The utility at $t+m$ with rebalancing every $k$ period equals the sum of the utilities at every subperiod: ${ }^{16}$

$$
U_{t+m}=\sum_{j=1}^{m / k} U_{t+k j} .
$$

Table 5 summarizes the results on cost-adjusted variances for various hedging horizons with weekly rebalancing. The numbers shown under each hedging-horizon header are the percentage increases in the utility which the corresponding strategies provide over the nohedging alternatives. The results show that the costs do not eclipse the gains from reduction, except for the combination of corn or wheat with the lowest risk aversion $(\lambda=2)$. At higher risk aversion levels, the expectations-based naive rules result in the highest utility increase, except for wheat at the one-week horizon. It is noted that its closest kin, the TTM-based naive rule, does not work at all for corn and wheat when transaction costs are considered: in all cases hedgers switch to the traditional naive rule. In addition, the GW test and DM test indicate that all significant differences are again in favor of the expectations-based naive rule. ${ }^{17}$ The only exception is soybeans for which the two-contract strategies are significantly beaten by their one-contract counterparts for all values of $\lambda$. The results are consistent with our earlier diagnosis that, for soybeans, the convenience yield risk is quite small and closely associated with price risk, such that the benefit from variance reduction via a second contract is wiped out by the transaction cost. Therefore, for soybeans the two-contract hedges are not useful. For soybeans, among the single-hedges, CCC-GARCH insignificantly beats OLs, except at the one-week horizon, while OLS wins against the naive hedge in 5 over 6 cases, of which 2 are significant. In Tables 9, 10 and 11, we report the results from GW test and DM test for $\lambda=8 .^{18}$

\footnotetext{
${ }^{16}$ One could argue that $(28)$ is not a regular Von Neumann-Morgenstern utility function like, say, expected utility under negative exponential preferences and normality. So, here, time-additive utility for (28) does not have the usual meaning. An alternative interpretation is that (28), with zero expectations, a variance is adjusted for transaction costs in a theoretically justified way, with relative risk aversion as the appropriate weight. Then, the sum is basically the sum of the variances adjusted for trading costs, which is close to the variance of the total return adjusted for costs.

${ }^{17}$ As the TTM-based naive rule does not work for corn and wheat, we do not include it in the GW and DM test.

${ }^{18}$ We can provide the results for other values of $\lambda$ upon request.
} 


\section{Conclusion}

This paper studies the use of two futures contracts in hedging an agricultural-commodity commitment or inventory position. We propose to use dual hedges not just for roll-over problems but also for delta hedges. Next to regression-based hedges using two contracts, we also propose a simple alternative that, like the naive one-for-one rule in a one-contract hedge, avoids both regression coefficients and theoretically perfect hedges that require restrictive assumptions. Instead, it is modestly heuristics-based and approximate, but under general assumptions. This approach results in a hedge ratio that depends on the expected convenience yield, the cost of carry and the time value in the futures contracts. Given its generality, this expectations-based naive strategy is easily applied to agricultural commodities for which some recently proposed strategies are not immediately suitable. To forecast convenience yields, we adopt the Carbonez, Nguyen and Sercu (2008) model. The resulting hedge ratio is still quite sensitive to noise when the forecasted yields for the two futures contracts are very similar. We therefore apply a robust exponential-smoothing method proposed by Gelper, Fried and Croux (2007). Tweaked to incorporate also local trend, this algorithm does a good job smoothing and solving the outliers problem in our first-pass heuristic hedge ratios. In order to compare the expectationsbased naive rule with its competitors, we evaluate both the variance reduction of the portfolio value and the utility gain after considering execution cost (i.e. the transaction-cost adjusted variance). We also add significance test for unconditional and conditional equality of the remaining risks (Diebold and Mariano, 2002; Giacomini and White, 2006). Lastly, we implement the hedging experiments both in a static and a dynamic fashion, i.e. without and with interim rebalancing.

Our results confirm that for hedging horizons exceeding one period (one week, in this paper), rebalancing does help to reduce the portfolio variance. Therefore, in our analysis we focus on this version. We find that two-contract hedges do better than single-contract ones, even in a pure delta-hedge situation where the horizon is shorter than the lives of the two futures used as hedge instruments. In terms of variance reduction, for most cases, the expectations-based naive rule does better than the regression based dual-hedges, OLS and CCC-GARCH (in that order). The expectations-based naive rules are only beaten 7 times out of 18 , not systematically by the same contender, and not significantly so (except at the oneweek horizon for corn). The smoothing of the hedge ratios has definitely contributed, even for regression models. The results also indicate that simplicity pays: OLS beats CCC-GARCH in most cases, whether the hedge is a single-or a dual-contract one. In terms of utility gains 
after transaction costs, lastly, for corn and wheat the expectations-based naive rule wins too, with only one (statistically insignificant) exception. However, for soybeans, the utility gains from the one-contract strategies are significantly higher than from the two-contract strategies, a feature that we can trace to the rather special covariance matrix.

\section{References}

Andersen, T.G. and T. Bollerslev (1998). "Answering the Skeptics: Yes, Standard Volatility Models Do Provide Accurate Forecasts." International Economics Review. 39: 885-905.

Baillie, R., R. Mayers (1991). "Bivariate GARCH Estimation of the Optimal Commodity Futures Hedge." Journal of Applied Economics. 6: 109-124. Bera, A.K, Garcia, P., Roh, J.S. (1997). "Estimation of Time-Varying Hedge Ratios for Corn and Soybeans: BGARCH and Random Coefficient Approaches". OFOR paper Number 97-06.

Bollerslev, T. (1990). "Modeling the Coherence in Short-Run Nominal Exchange Rates: A Multivariate Generalized ARCH Model." Review of Economics and Statistics. 72: 498-505.

Brennan, M. (1991). "The Price of Convenience and The Valuation of Commodity Contingent Claims." D.Lund and B. Oksendal (Editors), Stochastic models and option values. 33-71. Amsterdam: North-Holland.

Brennan, M., and N. Crew (1997). "Hedging Long Maturity Commodity Commitments with ShortDated Futures Contracts." M. Dempster and S. Pliska (Editors), Mathematics of derivative securities. 165-190. Cambridge: Cambridge University Press.

Carbonez, K.A.E., T.T.V. Nguyen and P. Sercu (2008). "Remodeling the Working Curve: The Roles of Scarcity, Time to Maturity and Time to Harvest". Working paper.

Lien, D. and Li Yang (2008). "Asymmetric Effect of Basis on Dynamic Futures Hedging: Empirical Evidence from Commodity Markets." The Journal of Banking and Finance. 32:187-198.

Diebold, F. X. and R.S. Mariano (1995). "Comparing Predictive Accuracy." Journal of Business and Economic Statistics. 13:253-263.

Diebold, F. X. and J.A. Lopez (1996). "Forecast Evaluation and Combination." in Handbook of Statistics. 14: Statistical Methods in Finance, ed. by G.S. Maddala and C.R. Rao. Amsterdam: North-Holland. 241-268.

Engle, R.F. (2002). "Dynamic Conditional Correlation: A New Simple Class of Multivariate Garch Models." The Journal of Business Economic Statistics. 20:339-350.

Ederington L. H. (1979). "The Hedging Performance of the New Futures Markets." The Journal of Finance. 20(1):157-170.

Fama, E.F., and K.R. French (1987). "Commodity Futures Prices: Some Evidence on Forecast Power, Premiums, and the Theory of Storage." The Journal of Business. 60(1):55-73.

Gelper, S., R. Fried and C. Croux (2007). "Robust Forecasting with Exponential and Holt-Winters Smoothing."

Giacomini, R., and H. White (2006). "Test of Conditional Predictive Ability." Econometrica. 74(6):15451578.

Gibson, R., and E. Schwartz (1990). "Stochastic Convenience Yield and the Pricing of Oil Contingent Claims." The Journal of Finance. 45(3):959-976.

Kroner, K.F., J. Sultan (1993). "Time Varying Distribution and Dynamic Hedging with Foreign Currency Futures." The Journal of Financial Quantitative Analysis. 28: 535-551. 
Schwartz, E.S. (1997). "The Stochastic Behavior of Commodity Prices: Implications for Valuation and Hedging." The Journal of Finance. 52:923-973.

Stein Jerome L. (1961). "The Simultaneous Determination of Spot and Futures Prices." The American Economic Review. 51(5):1012-1025.

Johnson Leland L. (1960). "The Theory of Hedging and Speculation in Commodity Futures." The Review of Economic Studies. 27(3):139-151.

Neuberger, A. (1999). "Hedging Long-Term Exposures with Multiple Short-Term Futures Contracts." The Review of Financial Studies. 12(3):429-459.

Ng, V.K. and S.C. Pirrong (1994). "Fundamental and Volatility: Storage, Spreads and the Dynamics of Metal Prices." Journal of Business. 67(2):203-230.

Pesaran, M.H., and Smith, R. (1995). "Estimating Long-run Relationship from Dynamic Heterogeneous Panels." Journal of Econometrics. 68, 79-113.

Sercu, P and R. Uppal (1995). International Financial Markets and The Firm. Southwestern Publishing/Thomson International, Cincinnatti, Ohio.

Sercu, P. and Wu, X. (2000). Cross- and delta-hedges: Regression- versus price-based hedge ratios. Journal of Banking and Finance, 24(5): 735 - 757.

Sercu, P. (2009). International Finance: Theory into Practice. Princeton University Press, Princeton, New Jersey.

Working, H. (1949). "The Theory of the Price of Storage." American Economic Review. 39:1254-1262.

Veld-Merkoulova, Y.V. and Frans A. De Roon (2003). "Hedging Long-term Commodity Risk." The Journal of Futures Markets. 23(2):109-133.

Zellner, A. (1969). "On the Aggregation Problem, a New Approach to a Troublesome Problem, Estimation and Risk Programming: Essays in honor of Gerhard Titner, Berlin, Springer." 
Hedging with Two Contracts: Simplicity Pays

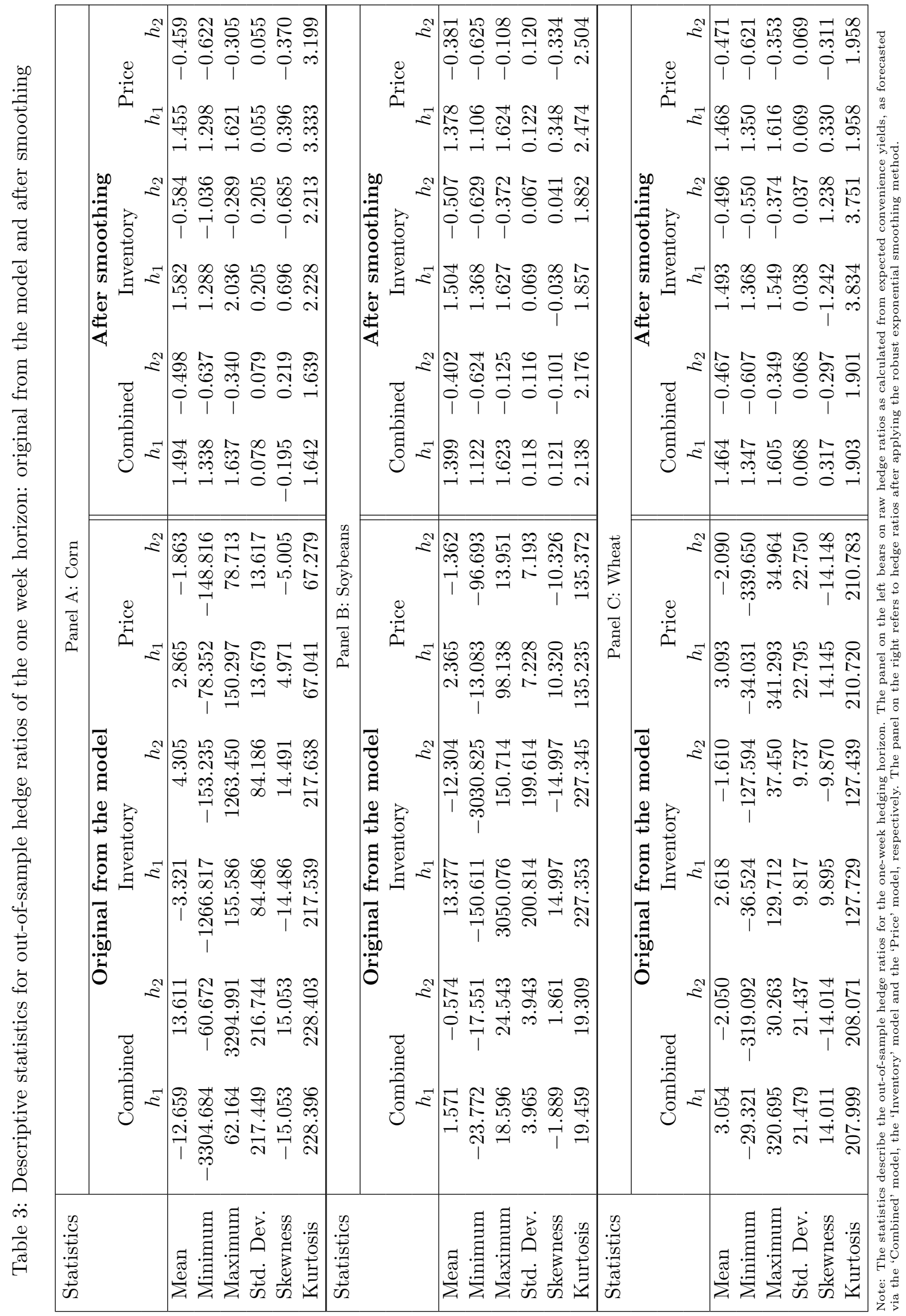




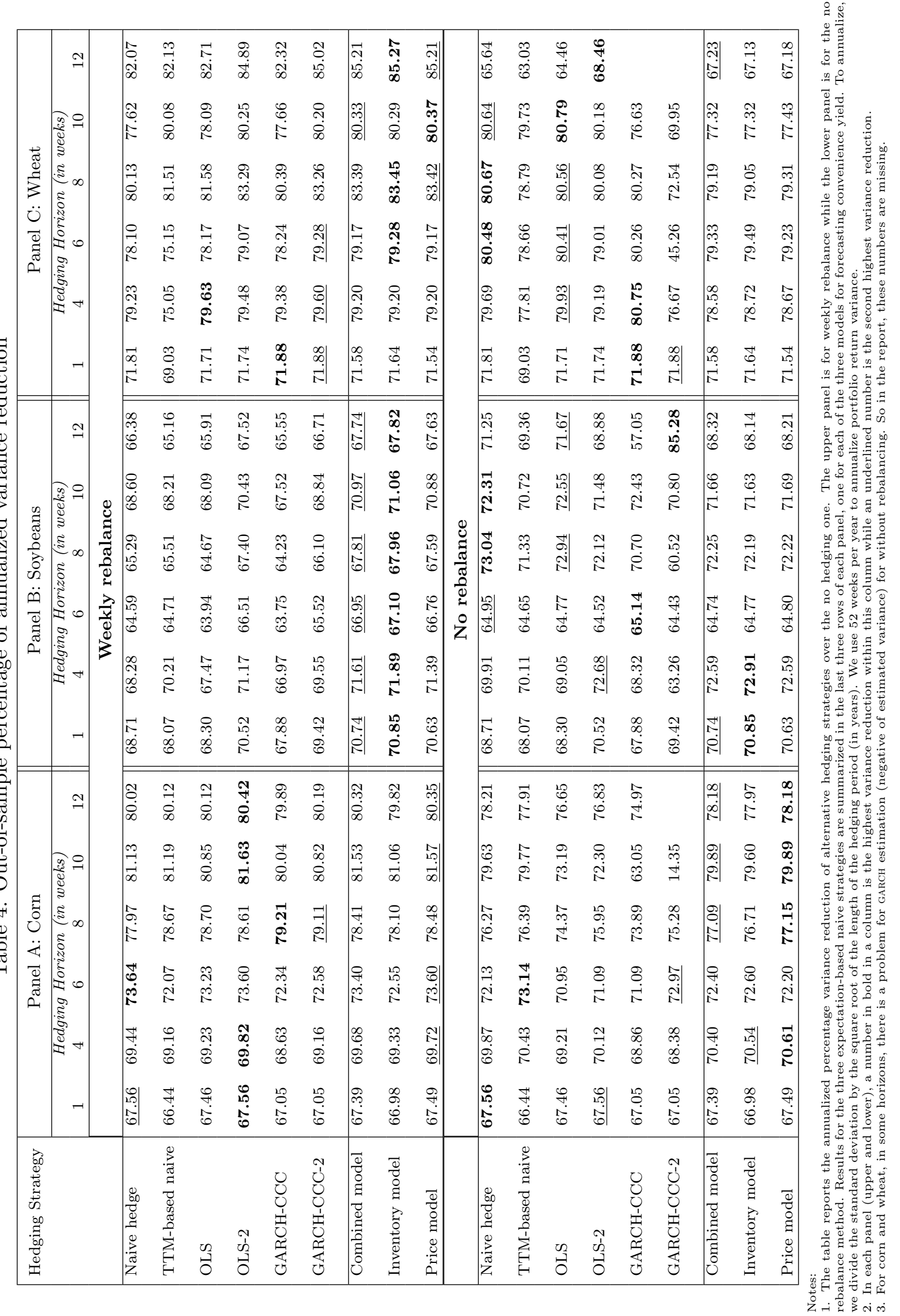




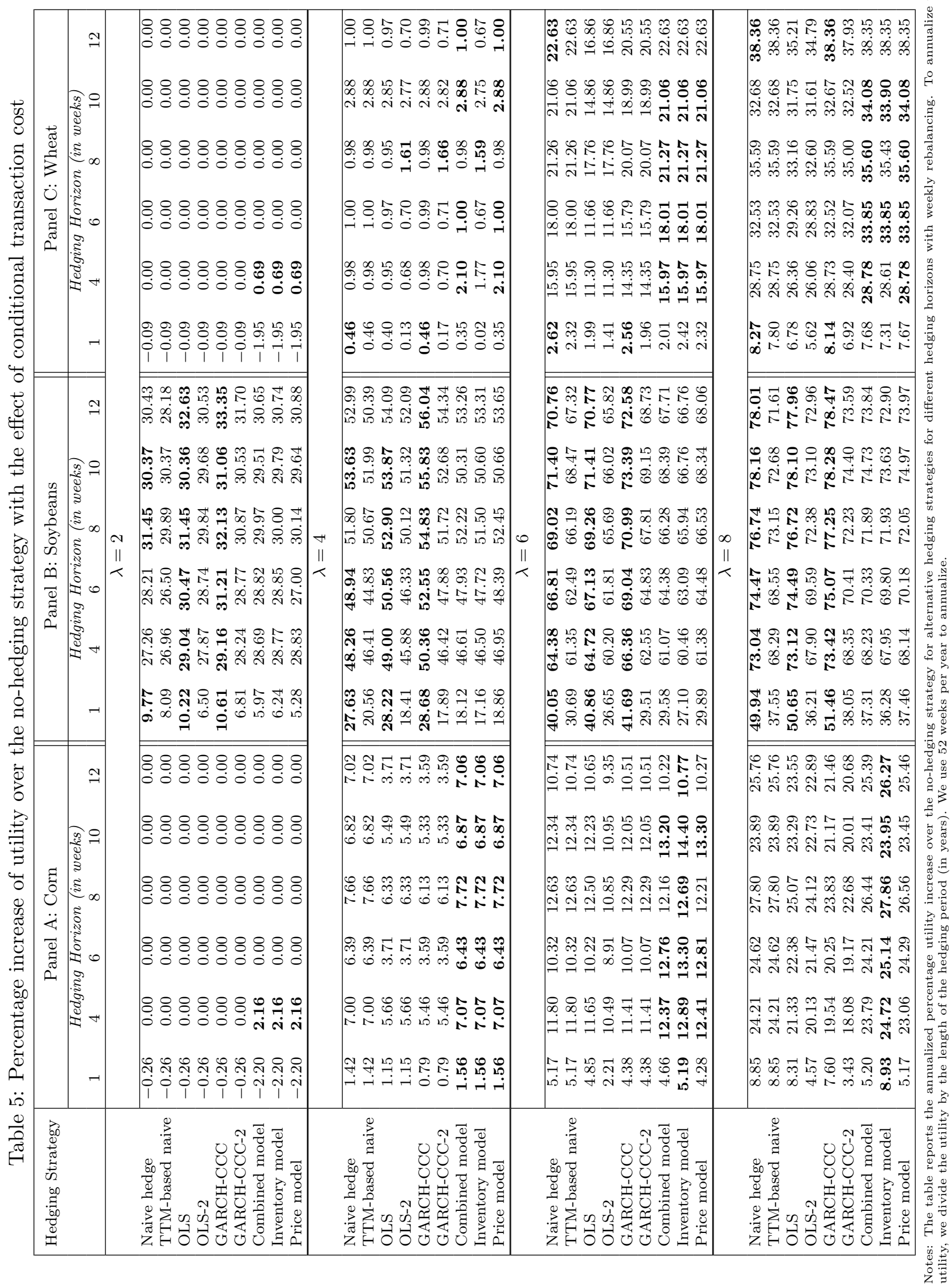


Table 6: Variance reduction comparisons for corn - weekly rebalancing

\begin{tabular}{|c|c|c|c|c|c|c|c|c|c|}
\hline & \multicolumn{9}{|c|}{ Panel A: 1 week hedging horizon } \\
\hline & \multirow{7}{*}{$\begin{array}{c}\text { TTM-based } \\
\text { naive }^{* *}\end{array}$} & OLS & OLS-2 & GARCH & GARCH-2 & Combined & \multirow[b]{2}{*}{ naive } & \multirow{2}{*}{\begin{tabular}{l|l} 
Price \\
naive
\end{tabular}} & Rank \\
\hline Naive hedge & & \multirow{6}{*}{$\begin{array}{l}\text { naive } \\
\text { ols }\end{array}$} & \multirow{6}{*}{$\begin{array}{l}\text { ols2 } \\
\text { ols2 } 2^{\text {** }} \\
\text { ols } 2\end{array}$} & \multirow{6}{*}{$\begin{array}{r}\text { naive } \\
\text { ccc } \\
\text { ols } \\
\text { ols2 }\end{array}$} & \multirow{4}{*}{$\begin{array}{c}\text { naive } \\
\text { ccc } 2 \\
\text { ols } \\
\text { ols } 2\end{array}$} & \multirow{6}{*}{$\begin{array}{c}\text { naive } \\
\text { comb } \\
\text { ols } \\
\text { ols } 2^{* *} \\
\text { comb } \\
\text { comb }\end{array}$} & & & 2 \\
\hline TTM-based naive & & & & & & & $i n v^{* *}$ & price $^{* *}$ & 9 \\
\hline OLS & & & & & & & ols & price & 4 \\
\hline OLS-2 & & & & & & & ols $2^{* *}$ & ols $2^{*}$ & 1 \\
\hline GARCH-CCC & & & & & $c c c$ & & $c c c$ & price & 6 \\
\hline GARCH-CCC-2 & & & & & & & $\operatorname{ccc} 2$ & price & 7 \\
\hline \multirow{5}{*}{$\begin{array}{l}\text { Combined model } \\
\text { Inventory model } \\
\text { Price model } \\
\end{array}$} & & & & & & & comb & price & 5 \\
\hline & & & & & & & & price* & 8 \\
\hline & & & & & & & & & 3 \\
\hline & & & Pan & el A: 4 & veek hed & ring horiz & & & \\
\hline & TTM-based & OLS & OLS-2 & GARCH & GARCH-2 & Combined & Inventory & Price & Rank \\
\hline Naive hedge & naive $^{\text {*k }}$ & naive & ols 2 & naive* & naive & comb & naive* & price & 4 \\
\hline TTM-based naive & & $o l s * *$ & ols $2^{* * * *}$ & $c c c$ & $\operatorname{ccc} 2^{* *}$ & $\operatorname{comb} b^{\text {*ak }}$ & $i n v^{* *}$ & price *⿻x & 9 \\
\hline OLS & & & ols 2 & ols* & ols & comb & $i n v$ & price & 6 \\
\hline OLS-2 & & & & ols $2^{* *}$ & ols 2 & ols 2 & $o l s 2$ & ols 2 & 1 \\
\hline GARCH-CCC & & & & & $\operatorname{ccc} 2$ & $\operatorname{comb}^{*}$ & inv & price $^{*}$ & 8 \\
\hline GARCH-CCC-2 & & & & & & $\mathrm{comb}$ & $i n v$ & price & 7 \\
\hline Combined model & & & & & & & comb & price & 3 \\
\hline Inventory model & & & & & & & & price & 5 \\
\hline Price model & & & & & & & & & 2 \\
\hline & & & Pan & el A: 6 & veek hed & sing horiz & & & \\
\hline & TTM-based & OLS & OLS-2 & GARCH & GARCH-2 & Combined & Inventory & Price & Rank \\
\hline Naive hedge & naive & naive & naive & naive & naive & naive & naive & naive & 1 \\
\hline TTM-based naive & & ols & $o l s 2^{* *}$ & $c c c$ & $c c c 2$ & $c o m b^{* *}$ & $i n v$ & price $^{* *}$ & 9 \\
\hline OLS & & & ols2 & ols* & ols & comb & ols & price & 5 \\
\hline OLS-2 & & & & ols 2 & ols $2 *$ & ols 2 & ols $2 *$ & price & 3 \\
\hline GARCH-CCC & & & & & $c c c 2$ & comb & inv & price & 8 \\
\hline GARCH-CCC-2 & & & & & & comb & $c c c 2$ & price* & 6 \\
\hline Combined model & & & & & & & $\mathrm{comb}^{*}$ & price ${ }^{* *}$ & 4 \\
\hline Inventory model & & & & & & & & price ${ }^{* *}$ & 7 \\
\hline Price model & & & & & & & & & 2 \\
\hline & & & Pan & el A: 8 & Neek hed & ring horiz & & & \\
\hline & TTM-based & OLS & OLS-2 & GARCH & GARCH-2 & Combined & Inventory & Price & Rank \\
\hline Naive hedge & naive 2 & ols & ols 2 & $c c c$ & $c c c 2$ & $c o m b$ & $i n v$ & price & 9 \\
\hline TTM-based naive & & ols & naive 2 & $c c c$ & $\operatorname{ccc} 2$ & naive 2 & naive 2 & naive 2 & 4 \\
\hline OLS & & & ols & $c c c$ & $\operatorname{ccc} 2$ & ols & ols & ols & 3 \\
\hline OLS-2 & & & & $c c c$ & $\operatorname{ccc} 2$ & ols 2 & $o l s 2$ & ols 2 & 5 \\
\hline GARCH-CCC & & & & & $c c c$ & $c c c$ & $c c c$ & $c c c$ & 1 \\
\hline GARCH-CCC-2 & & & & & & $\operatorname{ccc} 2$ & $\operatorname{ccc} 2$ & $\operatorname{ccc} 2$ & 2 \\
\hline Combined model & & & & & & & comb & price & 7 \\
\hline Inventory model & & & & & & & & price & 8 \\
\hline Price model & & & & & & & & & 6 \\
\hline & & & Pane & el A: 10 & week hec & ging hori & & & \\
\hline & TTM-based & OLS & OLS-2 & $\overline{\text { GARCH }}$ & GARCH-2 & Combined & Inventory & Price & Rank \\
\hline Naive hedge & naive 2 & naive & ols2 & naive & naive & $c o m b$ & naive & price & 5 \\
\hline TTM-based naive & & naive 2 & ols 2 & naive 2 & naive 2 & comb & naive 2 & price & 4 \\
\hline OLS & & & ols 2 & ols & $o l s$ & comb & inv & price & 7 \\
\hline OLS-2 & & & & ols 2 & ols 2 & ols 2 & ols 2 & ols 2 & 1 \\
\hline GARCH-CCC & & & & & $c c c 2$ & comb & $i n v$ & price & 9 \\
\hline GARCH-CCC-2 & & & & & & comb & inv & price & 8 \\
\hline Combined model & & & & & & & comb & price & 3 \\
\hline Inventory model & & & & & & & & price & 6 \\
\hline Price model & & & & & & & & & 2 \\
\hline & & & Pane & el A: 12 & week hec & ging hori & & & \\
\hline & TTM-based & OLS & OLS-2 & GARCH & GARCH-2 & Combined & Inventory & Price & Rank \\
\hline Naive hedge & naive 2 & ols & ols2 & naive & $\operatorname{ccc} 2$ & $c o m b$ & naive & price & 7 \\
\hline TTM-based naive & & naive 2 & ols 2 & naive 2 & $\operatorname{ccc} 2$ & comb & naive 2 & price & 5 \\
\hline OLS & & & ols 2 & ols & $\operatorname{ccc} 2$ & comb & ols & price & 6 \\
\hline OLS-2 & & & & ols 2 & ols 2 & ols 2 & ols 2 & ols 2 & 1 \\
\hline GARCH-CCC & & & & & $c c c 2$ & comb & $c c c$ & price & 8 \\
\hline GARCH-CCC- 2 & & & & & & comb & $c c c 2$ & price & 4 \\
\hline Combined model & & & & & & & $c o m b$ & price & 3 \\
\hline Inventory model & & & & & & & & price & 9 \\
\hline Price model & & & & & & & & & 2 \\
\hline
\end{tabular}

Notes:

1. The table provides summaries of the results from the DM test to compare the pairwise variance reductions with rebalancing. In the table, a cell shows the result for the comparison of the model mentioned in the column header and the row header, respectively. The entry in each cell is the name of the strategy that delivers the greater reduction in the conditional variance, as gauged by the DM test. This result is based on the sign of the coefficient for constant term on the regression of the difference of the two conditional variance $d v_{t}$ on constant with ols (Newey-West) estimation. naive, naive2, ols, ols2, ccc, ccc2 comb, inv, and price mean traditional naive hedge, TTM-based naive, one-contract OLS, two-contract OLS, one-contract CCC-GARCH, two-contract CCC-GARCH, expectations-based naive (with 'Inventory', 'Price' and 'Combined' model) strategy is the better one respectively.

2. Using the $p$-values of the GW test for the one-week horizon and DM test for other horizons, we also report via the familiar asterisks whether a strategy does significantly better than the other. ${ }^{* * *},{ }^{* *}$ and ${ }^{*}$ indicate the significant of the better model compared to the other at $1 \%$. $5 \%$ and $10 \%$ consecutively.

3. Competing strategies are ranked according to their pairwise comparison (9 strategies in total). The best strategy (ranked 1) is the strategy that does better than all other strategies. Next, the second best strategy (ranked 2) is the one that does better than all other remaining strategies (after taking out the ranked 1 strategy). All strategies are ranked like that. The last and worst strategy is ranked 9. 
Table 7: Variance reduction comparisons for soybeans - weekly rebalancing

\begin{tabular}{|c|c|c|c|c|c|c|c|c|c|}
\hline & \multicolumn{9}{|c|}{ Panel A: 1 week hedging horizon } \\
\hline & \multirow{7}{*}{$\begin{array}{c}\text { TTM-based } \\
\text { naive }\end{array}$} & \multirow{3}{*}{$\begin{array}{r}\text { naive } \\
\text { ols }\end{array}$} & \multirow{4}{*}{$\begin{array}{l}\text { OLS-2 } \\
\text { ols } 2 \\
\text { ols } 2 \text { ** } \\
\text { ols } 2\end{array}$} & \multirow{2}{*}{$\begin{array}{c}\text { GARCH } \\
\text { naive }\end{array}$} & GARCH-2 & Combined & Inventory & Price & Rank \\
\hline Naive hedge & & & & & $c c c 2$ & comb & $i n v$ & price & 6 \\
\hline TTM-based naive & & & & naive 2 & $c c c 2$ & $c o m b^{* *}$ & $i n v^{* *}$ & price ${ }^{* *}$ & 8 \\
\hline OLS & & & & $o l s s^{* * *}$ & $c c c 2$ & $c o m b$ & $i n v$ & price & 7 \\
\hline OLS-2 & & & & ols2 & ols $2^{* * *}$ & comb & $i n v$ & price & 4 \\
\hline GARCH-CCC & & & & & $\operatorname{ccc} 2$ & $\operatorname{comb}$ & $i n v$ & price & 9 \\
\hline GARCH-CCC- 2 & & & & & & $\operatorname{comb}^{*}$ & $i n v^{* *}$ & price* & 5 \\
\hline \multirow{5}{*}{$\begin{array}{l}\text { Combined model } \\
\text { Inventory model } \\
\text { Price model } \\
\end{array}$} & & & & & & & $i n v$ & comb & 2 \\
\hline & & & & & & & & $i n v$ & 1 \\
\hline & & & & & & & & & 3 \\
\hline & & & $\mathrm{Pa}$ & 1el A: 4 & week hed & ging horiz & & & \\
\hline & TTM-based & OLS & OLS-2 & GARCH & GARCH-2 & Combined & Inventory & $\begin{array}{ll}\text { Price } \\
\end{array}$ & Rank \\
\hline Naive hedge & naive 2 & naive & ols $2^{*}$ & naive & $\operatorname{ccc} 2$ & comb & $i n v$ & price $^{*}$ & 7 \\
\hline TTM-based naive & & naive 2 & ols $2^{*}$ & naive 2 & naive 2 & $\operatorname{comb} b^{\text {** }}$ & $i n v^{* *}$ & price $^{* *}$ & 5 \\
\hline OLS & & & ols 2 & $o l s * *$ & $\operatorname{ccc} 2$ & comb & $i n v$ & price & 8 \\
\hline OLS-2 & & & & ols $2^{*}$ & ols $2 *$ & comb & $i n v$ & price & 4 \\
\hline GARCH-CCC & & & & & $\operatorname{ccc} 2$ & $c o m b$ & $i n v$ & price & 9 \\
\hline GARCH-CCC-2 & & & & & & $\operatorname{comb}^{*}$ & $i n v$ & price* & 6 \\
\hline Combined model & & & & & & & inv & comb & 2 \\
\hline Inventory model & & & & & & & & $i n v$ & 1 \\
\hline Price model & & & & & & & & & 3 \\
\hline & & & $\mathrm{Pa}$ & lel A: 6 & week hed & ging horiz & & & \\
\hline & TTM-based & OLS & OLS-2 & GARCH & GARCH-2 & Combined & Inventory & Price & Rank \\
\hline Naive hedge & naive 2 & naive & ols 2 & naive & $\operatorname{ccc} 2$ & comb & $i n v$ & price & 7 \\
\hline TTM-based naive & & naive 2 & ols 2 & naive 2 & $\operatorname{ccc} 2$ & $\operatorname{comb} b^{* *}$ & $i n v^{* *}$ & price $^{* *}$ & 6 \\
\hline OLS & & & ols 2 & ols & $\operatorname{ccc} 2$ & comb & $i n v$ & price & 8 \\
\hline OLS-2 & & & & ols 2 & ols 2 & comb & $i n v$ & price & 4 \\
\hline GARCH-CCC & & & & & $c c c 2$ & comb & $i n v$ & price & 9 \\
\hline GARCH-CCC-2 & & & & & & comb & $i n v$ & price & 5 \\
\hline Combined model & & & & & & & inv & comb & 2 \\
\hline Inventory model & & & & & & & & inv & 1 \\
\hline Price model & & & & & & & & & 3 \\
\hline & & & $\mathrm{Pa}$ & 1el A: 8 & week hed & ging horiz & & & \\
\hline & TTM-based & OLS & OLS-2 & GARCH & GARCH-2 & Combined & Inventory & Price & Rank \\
\hline Naive hedge & naive 2 & naive & ols2 & naive & $\operatorname{ccc} 2$ & comb & $i n v$ & price & 7 \\
\hline TTM-based naive & & naive 2 & ols $2^{* *}$ & naive 2 & $\operatorname{ccc} 2$ & $\operatorname{comb} b^{* *}$ & $i n v^{* *}$ & price ${ }^{* *}$ & 6 \\
\hline OLS & & & ols 2 & ols & $\operatorname{ccc} 2$ & $c o m b$ & $i n v$ & price & 8 \\
\hline OLS-2 & & & & ols 2 & ols 2 & comb & $i n v$ & price & 4 \\
\hline GARCH-CCC & & & & & $c c c 2$ & comb & $i n v$ & price & 9 \\
\hline GARCH-CCC-2 & & & & & & comb & $i n v$ & price & 5 \\
\hline Combined model & & & & & & & inv & comb & 2 \\
\hline Inventory model & & & & & & & & $i n v$ & 1 \\
\hline Price model & & & & & & & & & 3 \\
\hline & & & Pal & el A: 10 & week her & ging hori & & & \\
\hline & TTM-based & OLS & OLS-2 & GARCH & GARCH-2 & Combined & Inventory & Price & Rank \\
\hline Naive hedge & naive & naive & ols2 & naive & $\operatorname{ccc} 2$ & comb & $i n v$ & price & 6 \\
\hline TTM-based naive & & naive 2 & ols $2^{* *}$ & naive 2 & $c c c 2$ & $c o m b^{\text {** }}$ & $i n v^{* *}$ & price ${ }^{* *}$ & 7 \\
\hline OLS & & & ols2 & ols & $\operatorname{ccc} 2$ & comb & $i n v$ & price & 8 \\
\hline OLS-2 & & & & ols 2 & $o l s 2^{*}$ & comb & $i n v$ & price & 4 \\
\hline GARCH-CCC & & & & & $c c c 2$ & $c o m b$ & $i n v$ & price & 9 \\
\hline GARCH-CCC-2 & & & & & & comb & $i n v$ & price & 5 \\
\hline Combined model & & & & & & & $i n v$ & comb & 2 \\
\hline Inventory model & & & & & & & & $i n v$ & 1 \\
\hline Price model & & & & & & & & & 3 \\
\hline & & & $\mathrm{Pa}$ & el A: 12 & week hec & ging hori & & & \\
\hline & TTM-based & OLS & OLS-2 & GARCH & GARCH-2 & Combined & Inventory & Price & Rank \\
\hline Naive hedge & naive & naive & ols 2 & naive & $\operatorname{ccc} 2$ & comb & $i n v$ & price & 6 \\
\hline TTM-based naive & & ols & ols $2 *$ & $c c c$ & $\operatorname{ccc} 2$ & $\operatorname{comb} b^{\text {** }}$ & $i n v^{* *}$ & price ${ }^{* *}$ & 9 \\
\hline OLS & & & ols2 & ols & $\operatorname{ccc} 2$ & comb & $i n v$ & price & 7 \\
\hline OLS-2 & & & & ols 2 & ols 2 & comb & $i n v$ & price & 4 \\
\hline GARCH-CCC & & & & & $c c c 2$ & comb & $i n v$ & price & 8 \\
\hline GARCH-CCC-2 & & & & & & comb & $i n v$ & price & 5 \\
\hline Combined model & & & & & & & $i n v$ & comb & 2 \\
\hline Inventory model & & & & & & & & $i n v$ & 1 \\
\hline Price model & & & & & & & & & 3 \\
\hline
\end{tabular}

Notes:

1. The table provides summaries of the results from the DM test to compare the pairwise variance reductions with rebalancing. In the table, a cell shows the result for the comparison of the model mentioned in the column header and the row header, respectively. The entry in each cell is the name of the strategy that delivers the greater reduction in the conditional variance, as gauged by the DM test. This result is based on the sign of the coefficient for constant term on the regression of the difference of the two conditional variance $d v_{t}$ on constant with ols (Newey-West) estimation. naive, naive2, ols, ols2, ccc, ccc2 comb, inv, and price mean traditional naive hedge, TTM-based naive, one-contract OLS, two-contract OLS, one-contract CCC-GARCH, two-contract CCC-GARCH, expectations-based naive (with 'Inventory', 'Price' and 'Combined' model) strategy is the better one respectively.

2. Using the $p$-values of the GW test for the one-week horizon and DM test for other horizons, we also report via the familiar asterisks whether a strategy does significantly better than the other. ${ }^{* * *},{ }^{* *}$ and ${ }^{*}$ indicate the significant of the better model compared to the other at $1 \%$. $5 \%$ and $10 \%$ consecutively.

3. Competing strategies are ranked according to their pairwise comparison (9 strategies in total). The best strategy (ranked 1) is the strategy that does better than all other strategies. Next, the second best strategy (ranked 2) is the one that does better than all other remaining strategies (after taking out the ranked 1 strategy). All strategies are ranked like that. The last and worst strategy is ranked 9. 
Table 8: Variance reduction comparisons for wheat - weekly rebalancing

\begin{tabular}{|c|c|c|c|c|c|c|c|c|c|}
\hline & \multicolumn{9}{|c|}{ Panel A: 1 week hedging horizon } \\
\hline & TTM-based & OLS & OLS-2 & GARCH & $\overline{\text { GARCH-2 }}$ & Combined & Inventory & Price & Rank \\
\hline $\begin{array}{l}\text { Naive hedge } \\
\text { TTM-based naive } \\
\text { OLS } \\
\text { OLS-2 } \\
\text { GARCH-CCC } \\
\text { GARCH-CCC-2 }\end{array}$ & naive $^{*}$ & $\begin{array}{r}\text { naive } \\
\text { ols }\end{array}$ & $\begin{array}{l}\text { naive } \\
\text { ols } 2^{* *} \\
\text { ols } 2\end{array}$ & $\begin{array}{l}c c c \\
c c c^{*} \\
c c c \\
c c c\end{array}$ & $\begin{array}{l}c c c 2 \\
c c c 2^{* *} \\
c c c 2 \\
c c c 2 \\
c c c\end{array}$ & $\begin{array}{l}\text { naive } \text { comb } \\
\text { ols } \\
\text { ols } 2 \\
\text { ccc } \\
\text { ccc2 }\end{array}$ & $\begin{array}{l}\text { naive } \\
\text { inv } \\
\text { ols } \\
\text { ols2 } \\
c c c \\
c c c 2\end{array}$ & $\begin{array}{c}\text { naive } \\
\text { price } \\
\text { ols } \\
\text { ols2 } \\
c c c \\
c c c 2\end{array}$ & $\begin{array}{l}3 \\
9 \\
5 \\
4 \\
1 \\
2\end{array}$ \\
\hline \multirow[t]{2}{*}{$\begin{array}{l}\text { Combined model } \\
\text { Inventory model } \\
\text { Price model }\end{array}$} & & & & & & & $i n v^{\text {*a }}$ & $\begin{array}{c}\operatorname{comb} b \\
i n v^{* *}\end{array}$ & $\begin{array}{l}2 \\
7 \\
6 \\
8\end{array}$ \\
\hline & \multicolumn{9}{|c|}{ Panel A: 4 week hedging horizon } \\
\hline $\begin{array}{l}\text { Naive hedge } \\
\text { TTM-based naive } \\
\text { OLS } \\
\text { OLS-2 } \\
\text { GARCH-CCC } \\
\text { GARCH-CCC-2 }\end{array}$ & $\begin{array}{c}\text { TTM-based } \\
\text { naive }^{*}\end{array}$ & $\begin{array}{c}\text { OLS } \\
o l s \\
o l s^{*}\end{array}$ & $\begin{array}{l}\text { OLS-2 } \\
\text { ols2 } \\
\text { ols } 22^{* *} \\
\text { ols }\end{array}$ & $\begin{array}{c}\text { GARCH } \\
c c c \\
c c c^{*} \\
\text { ols } \\
\text { ols } 2\end{array}$ & $\begin{array}{l}\text { GARCH-2 } \\
c c c 2 \\
c c c 2^{* *} \\
\text { ols } \\
c c c 2 \\
c c c 2\end{array}$ & $\begin{array}{c}\text { Combined } \\
\text { naive } \\
\text { comb } \\
\text { ols } \\
\text { ols } 2 \\
\text { ccc } \\
\text { ccc } 2\end{array}$ & $\begin{array}{c}\text { Inventory } \\
\text { naive } \\
\text { inv } \\
\text { ols } \\
\text { ols } 2 \\
\text { ccc } \\
\text { ccc } 2\end{array}$ & \begin{tabular}{|c|} 
Price \\
naive \\
price \\
ols \\
ols2 \\
$c c c$ \\
$c c c 2$ \\
\end{tabular} & $\begin{array}{c}\text { Rank } \\
5 \\
9 \\
1 \\
3 \\
4 \\
2 \\
\end{array}$ \\
\hline \multirow[t]{3}{*}{$\begin{array}{l}\text { Combined model } \\
\text { Inventory model } \\
\text { Price model }\end{array}$} & & & & & & & $c o m b$ & $\begin{array}{c}\text { comb } \\
\text { inv }\end{array}$ & $\begin{array}{l}6 \\
7 \\
8 \\
\end{array}$ \\
\hline & \multicolumn{9}{|c|}{ Panel A: 6 week hedging horizon } \\
\hline & TTM-based & OLS & OLS-2 & GARCH & GARCH-2 & Combined & Inventory & Price & Rank \\
\hline $\begin{array}{l}\text { Naive hedge } \\
\text { TTM-based naive } \\
\text { OLS } \\
\text { OLS-2 } \\
\text { GARCH-CCC } \\
\text { GARCH-CCC-2 } \\
\end{array}$ & naive & $\begin{array}{l}\text { ols } \\
\text { ols }\end{array}$ & $\begin{array}{l}\text { ols2 } \\
\text { ols2 } \\
\text { ols2 }\end{array}$ & $\begin{array}{r}c c c \\
c c c \\
c c c \\
o l s 2\end{array}$ & $\begin{array}{l}c c c 2 \\
c c c 2 \\
c c c 2 \\
c c c 2 \\
c c c 2\end{array}$ & $\begin{array}{l}\text { comb } \\
\text { comb } \\
\text { comb } \\
\text { comb } \\
\text { comb } \\
\text { ccc2 } \\
\end{array}$ & $\begin{array}{l}i n v \\
i n v \\
i n v \\
i n v \\
i n v \\
i n v \\
\end{array}$ & \begin{tabular}{|l|} 
price \\
price \\
price \\
price \\
price \\
ccc2 \\
\end{tabular} & $\begin{array}{l}8 \\
9 \\
7 \\
5 \\
6 \\
2 \\
\end{array}$ \\
\hline \multirow[t]{3}{*}{$\begin{array}{l}\text { Combined model } \\
\text { Inventory model } \\
\text { Price model }\end{array}$} & & & & & & & $i n v^{*}$ & $\begin{array}{c}c o m b^{* *} \\
i n v^{* * *}\end{array}$ & $\begin{array}{l}3 \\
1 \\
4 \\
\end{array}$ \\
\hline & \multicolumn{9}{|c|}{ Panel A: 8 week hedging horizon } \\
\hline & TTM-based & OLS & OLS-2 & GARCH & GARCH-2 & Combined & Inventory & Price & Rank \\
\hline $\begin{array}{l}\text { Naive hedge } \\
\text { TTM-based naive } \\
\text { OLS } \\
\text { OLS-2 } \\
\text { GARCH-CCC } \\
\text { GARCH-CCC-2 }\end{array}$ & naive 2 & $\begin{array}{l}\text { ols } \\
\text { ols }\end{array}$ & $\begin{array}{l}\text { ols2 } \\
\text { ols2 } 2 \\
\text { ols } 2^{*}\end{array}$ & $\begin{array}{r}c c c \\
\text { naive2 } \\
\text { ols } \\
\text { ols2 }\end{array}$ & $\begin{array}{l}\text { ccc2 } \\
\text { ccc2 } \\
\text { ccc2 } 2^{* *} \\
\text { ols } 2 \\
\text { ccc2 }\end{array}$ & $\begin{array}{l}\text { comb } \\
\text { comb } \\
\text { comb } \\
\text { comb } \\
\text { comb } \\
\text { comb }\end{array}$ & $\begin{array}{l}\text { inv } \\
i n v \\
i n v^{*} \\
i n v \\
i n v \\
i n v\end{array}$ & $\begin{array}{l}\text { price } \\
\text { price } \\
\text { price* } \\
\text { price } \\
\text { price } \\
\text { price }\end{array}$ & $\begin{array}{l}9 \\
7 \\
6 \\
4 \\
8 \\
5\end{array}$ \\
\hline \multirow[t]{2}{*}{$\begin{array}{l}\text { Combined model } \\
\text { Inventory model } \\
\text { Price model }\end{array}$} & & & & & & & inv & $\begin{array}{c}\text { price } \\
\text { inv }\end{array}$ & $\begin{array}{l}3 \\
1 \\
2 \\
\end{array}$ \\
\hline & \multicolumn{9}{|c|}{ Panel A: 10 week hedging horizon } \\
\hline $\begin{array}{l}\text { Naive hedge } \\
\text { TTM-based naive } \\
\text { OLS } \\
\text { OLS-2 } \\
\text { GARCH-CCC } \\
\text { GARCH-CCC-2 }\end{array}$ & $\begin{array}{l}\text { TTM-based } \\
\text { naive2 }\end{array}$ & $\begin{array}{c}\text { OLS } \\
\text { ols } \\
\text { naive2 }\end{array}$ & $\begin{array}{c}\text { OLS-2 } \\
\text { ols } 2 \\
\text { ols2 } \\
\text { ols2 }\end{array}$ & $\begin{array}{r}\text { GARCH } \\
\text { ccc } \\
\text { naive } 2 \\
\text { ols } \\
\text { ols } 2\end{array}$ & $\begin{array}{l}\text { GARCH-2 } \\
c c c 2^{*} \\
c c 22 \\
c c c 2 \\
\text { ols } 2 \\
\text { ccc } 2^{*}\end{array}$ & $\begin{array}{l}\text { Combined } \\
\text { comb } \\
\text { comb } \\
\text { comb } \\
\text { comb } \\
\text { comb } \\
\text { comb }\end{array}$ & $\begin{array}{c}\text { Inventory } \\
i n v \\
i n v \\
i n v \\
i n v \\
i n v \\
i n v\end{array}$ & $\begin{array}{l}\text { Price } \\
\text { price } \\
\text { price } \\
\text { price } \\
\text { price } \\
\text { price } \\
\text { price } \\
\end{array}$ & $\begin{array}{c}\text { Rank } \\
9 \\
6 \\
7 \\
4 \\
8 \\
5 \\
\end{array}$ \\
\hline \multirow[t]{3}{*}{$\begin{array}{l}\text { Combined model } \\
\text { Inventory model } \\
\text { Price model }\end{array}$} & & & & & & & comb & $\begin{array}{l}\text { price } \\
\text { price }\end{array}$ & $\begin{array}{l}2 \\
3 \\
1 \\
\end{array}$ \\
\hline & \multicolumn{9}{|c|}{ Panel A: 12 week hedging horizon } \\
\hline & TTM-based & OLS & $\overline{\text { OLS-2 }}$ & GARCH & GARCH-2 & Combined & Inventory & Price & Rank \\
\hline $\begin{array}{l}\text { Naive hedge } \\
\text { TTM-based naive } \\
\text { OLS } \\
\text { OLS-2 } \\
\text { GARCH-CCC } \\
\text { GARCH-CCC-2 }\end{array}$ & naive2 2 & $\begin{array}{l}\text { ols } \\
\text { ols }\end{array}$ & $\begin{array}{l}\text { ols2 } \\
\text { ols2 } \\
\text { ols2 }\end{array}$ & $\begin{array}{l}c c c^{*+1} \\
c c c \\
o l s \\
o l s 2\end{array}$ & $\begin{array}{l}c c c 2 \\
c c c 2 \\
c c c 2 \\
c c c 2 \\
c c c 2\end{array}$ & $\begin{array}{l}\operatorname{comb} \\
\text { comb } \\
\text { comb } \\
\text { comb } \\
\text { comb } \\
\text { comb }\end{array}$ & $\begin{array}{l}\text { inv } \\
i n v^{*} \\
i n v \\
i n v \\
i n v \\
i n v\end{array}$ & $\begin{array}{l}\text { price } \\
\text { price* } \\
\text { price } \\
\text { price } \\
\text { price } \\
\text { price }\end{array}$ & $\begin{array}{l}9 \\
8 \\
6 \\
5 \\
7 \\
4\end{array}$ \\
\hline $\begin{array}{l}\text { Combined model } \\
\text { Inventory model } \\
\text { Price model }\end{array}$ & & & & & & & $i n v$ & $\begin{array}{c}\text { price } \\
\text { inv }\end{array}$ & $\begin{array}{l}3 \\
1 \\
2\end{array}$ \\
\hline
\end{tabular}

Notes:

1. The table provides summaries of the results from the DM test to compare the pairwise variance reductions with rebalancing. In the table a cell shows the result for the comparison of the model mentioned in the column header and the row header, respectively. The entry in each cell is the name of the strategy that delivers the greater reduction in the conditional variance, as gauged by the DM test. This result is based on the sign of the coefficient for constant term on the regression of the difference of the two conditional variance $d v_{t}$ on constant with ols (Newey-West) estimation. naive, naive2, ols, ols2, ccc, ccc2 comb, inv, and price mean traditional naive hedge, TTM-based naive, one-contract OLS, two-contract OLS, one-contract CCC-GARCH, two-contract CCC-GARCH, expectations-based naive (with 'Inventory', 'Price' and 'Combined' model) strategy is the better one respectively.

2. Using the $p$-values of the GW test for the one-week horizon and DM test for other horizons, we also report via the familiar asterisks whether a strategy does significantly better than the other. ${ }^{* * *},{ }^{* *}$ and ${ }^{*}$ indicate the significant of the better model compared to the other at $1 \%$. $5 \%$ and $10 \%$ consecutively.

3. Competing strategies are ranked according to their pairwise comparison (9 strategies in total). The best strategy (ranked 1) is the strategy that does better than all other strategies. Next, the second best strategy (ranked 2) is the one that does better than all other remaining strategies (after taking out the ranked 1 strategy). All strategies are ranked like that. The last and worst strategy is ranked 9. 
Table 9: Utility gain comparisons for corn - weekly rebalancing - $\lambda=8$

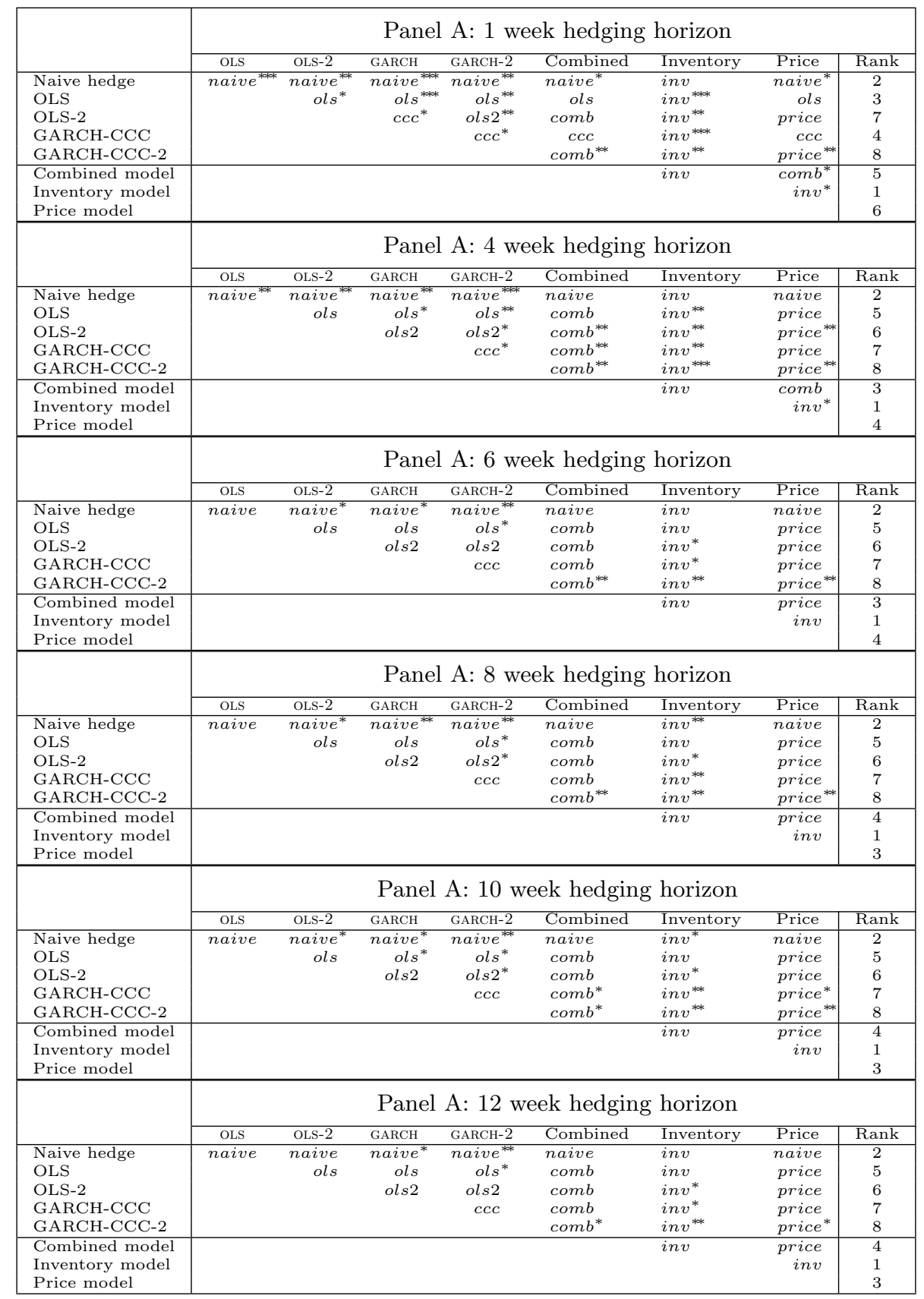

Notes:

1. The table provides summaries of the results from the DM test to compare the utility pairwise after taking into account the conditional transaction cost with weekly rebalancing. In the table, a cell shows the result for the comparison of the model mentioned in the column header and the row header, respectively. The entry in each cell is the name of the strategy that delivers the greater increase in the utility, as gauged by the DM test. This result is based on the sign of the coefficient for constant term on the regression of the difference of the two utility $d u_{t}$ on constant oLs (Newey-West) estimation. naive, naive2, ols, ols2, ccc, ccc 2 comb, inv, and price mean traditional naive hedge, TTM-based naive, one-contract OLS, two-contract OLS, one-contract CCC-GARCH, two-contract CCC-GARCH, expectations-based naive (with 'Inventory', 'Price' and 'Combined' model) strategy is the better one respectively.

2. Using the $p$-values of the GW test for the one-week horizon and DM test for other horizons, we also report via the familiar asterisks whether a strategy does significantly better than the other. ${ }^{* * *},{ }^{* *}$ and ${ }^{*}$ indicate the significant of the better model compared to the other at $1 \%$. $5 \%$ and $10 \%$ consecutively.

3. Competing strategies are ranked according to their pairwise comparison ( 8 strategies in total). The best strategy (ranked 1 ) is the strategy that does better than all other strategies. Next, the second best strategy (ranked 2) is the one that does better than all other remaining strategies (after taking out the ranked 1 strategy). All strategies are ranked like that. The last and worst strategy is ranked 8. 
Table 10: Utility gain comparisons for soybeans - weekly rebalancing - $\lambda=8$

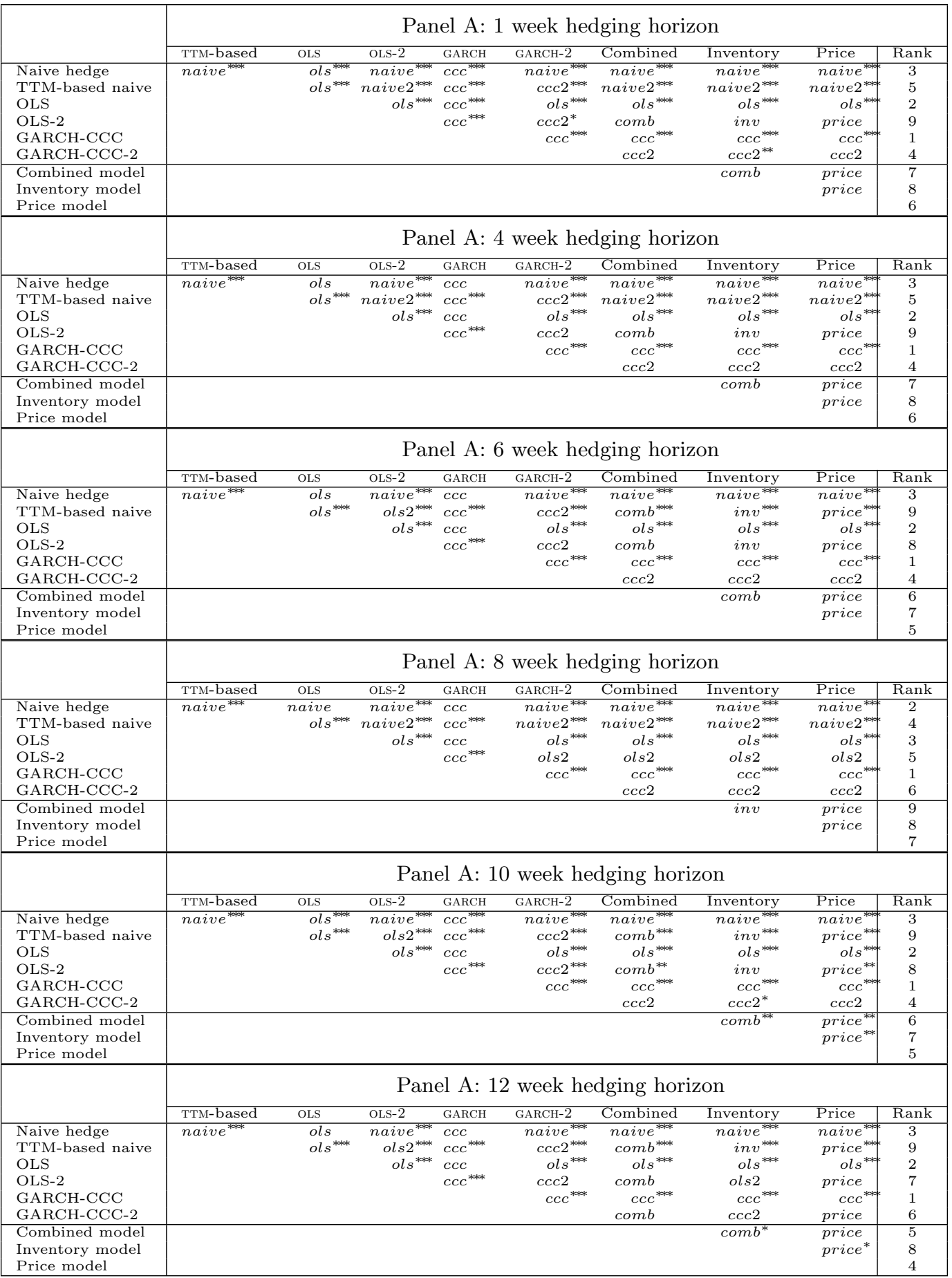

Notes:

1. The table provides summaries of the results from the DM test to compare the utility pairwise after taking into account the conditional transaction cost with weekly rebalancing. In the table, a cell shows the result for the comparison of the model mentioned in the column header and the row header, respectively. The entry in each cell is the name of the strategy that delivers the greater increase in the utility, as gauged by the DM test. This result is based on the sign of the coefficient for constant term on the regression of the difference of the two utility $d u_{t}$ on constant oLS (Newey-West) estimation. naive, naive 2 , ols, ols 2 , ccc, ccc 2 comb, inv, and price mean traditional naive hedge, TTM-based naive, one-contract OLS, two-contract OLS, one-contract CCC-GARCH, two-contract CCC-GARCH, expectations-based naive (with 'Inventory', 'Price' and 'Combined' model) strategy is the better one respectively.

2. Using the $p$-values of the GW test for the one-week horizon and DM test for other horizons, we also report via the familiar asterisks whether a strategy does significantly better than the other. ${ }^{* * *},{ }^{* *}$ and ${ }^{*}$ indicate the significant of the better model compared to the other at $1 \%$. $5 \%$ and $10 \%$ consecutively.

3. Competing strategies are ranked according to their pairwise comparison (9 strategies in total). The best strategy (ranked 1) is the strategy that does better than all other strategies. Next, the second best strategy (ranked 2) is the one that does better than all other remaining strategies (after taking out the ranked 1 strategy). All strategies are ranked like that. The last and worst strategy is ranked 9. 
Table 11: Utility gain comparisons for wheat - weekly rebalancing - $\lambda=8$

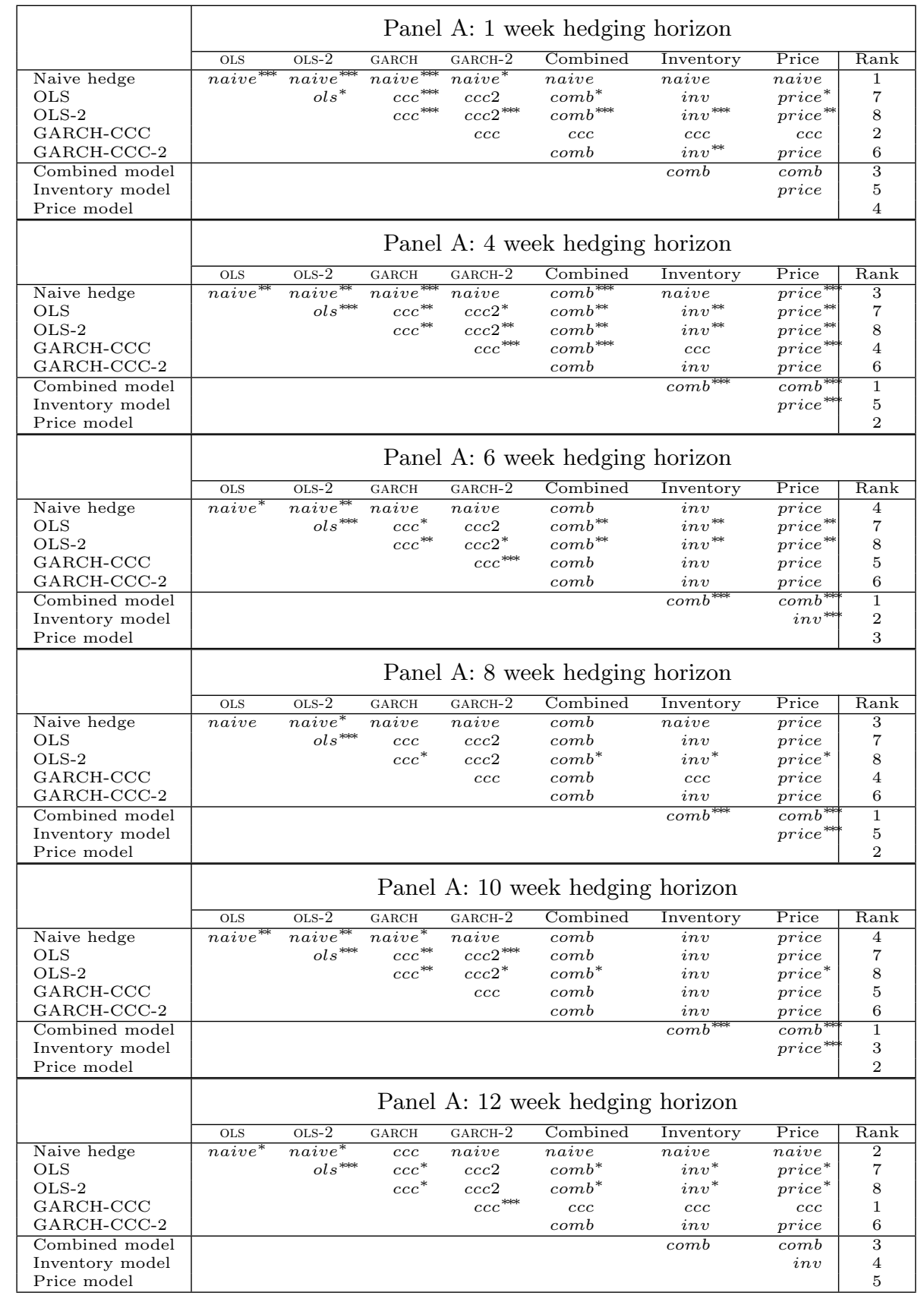

Notes:

1. The table provides summaries of the results from the DM test to compare the utility pairwise after taking into account the conditional transaction cost with weekly rebalancing. In the table, a cell shows the result for the comparison of the model mentioned in the column header and the row header, respectively. The entry in each cell is the name of the strategy that delivers the greater increase in the utility, as gauged by the DM test. This result is based on the sign of the coefficient for constant term on the regression of the difference of the two utility $d u_{t}$ on constant oLs (Newey-West) estimation. naive, naive2, ols, ols2, ccc, ccc 2 comb, inv, and price mean traditional naive hedge, TTM-based naive, one-contract OLS, two-contract OLS, one-contract CCC-GARCH, two-contract CCC-GARCH, expectations-based naive (with 'Inventory', 'Price' and 'Combined' model) strategy is the better one respectively.

2. Using the $p$-values of the GW test for the one-week horizon and DM test for other horizons, we also report via the familiar asterisks whether a strategy does significantly better than the other. ${ }^{* * *}$, ${ }^{*}$ and ${ }^{*}$ indicate the significant of the better model compared to the other at $1 \%$. $5 \%$ and $10 \%$ consecutively.

3. Competing strategies are ranked according to their pairwise comparison ( 8 strategies in total). The best strategy (ranked 1) is the strategy that does better than all other strategies. Next, the second best strategy (ranked 2) is the one that does better than all other remaining strategies (after taking out the ranked 1 strategy). All strategies are ranked like that. The last and worst strategy is ranked 8. 
Hedging with Two Contracts: Simplicity Pays

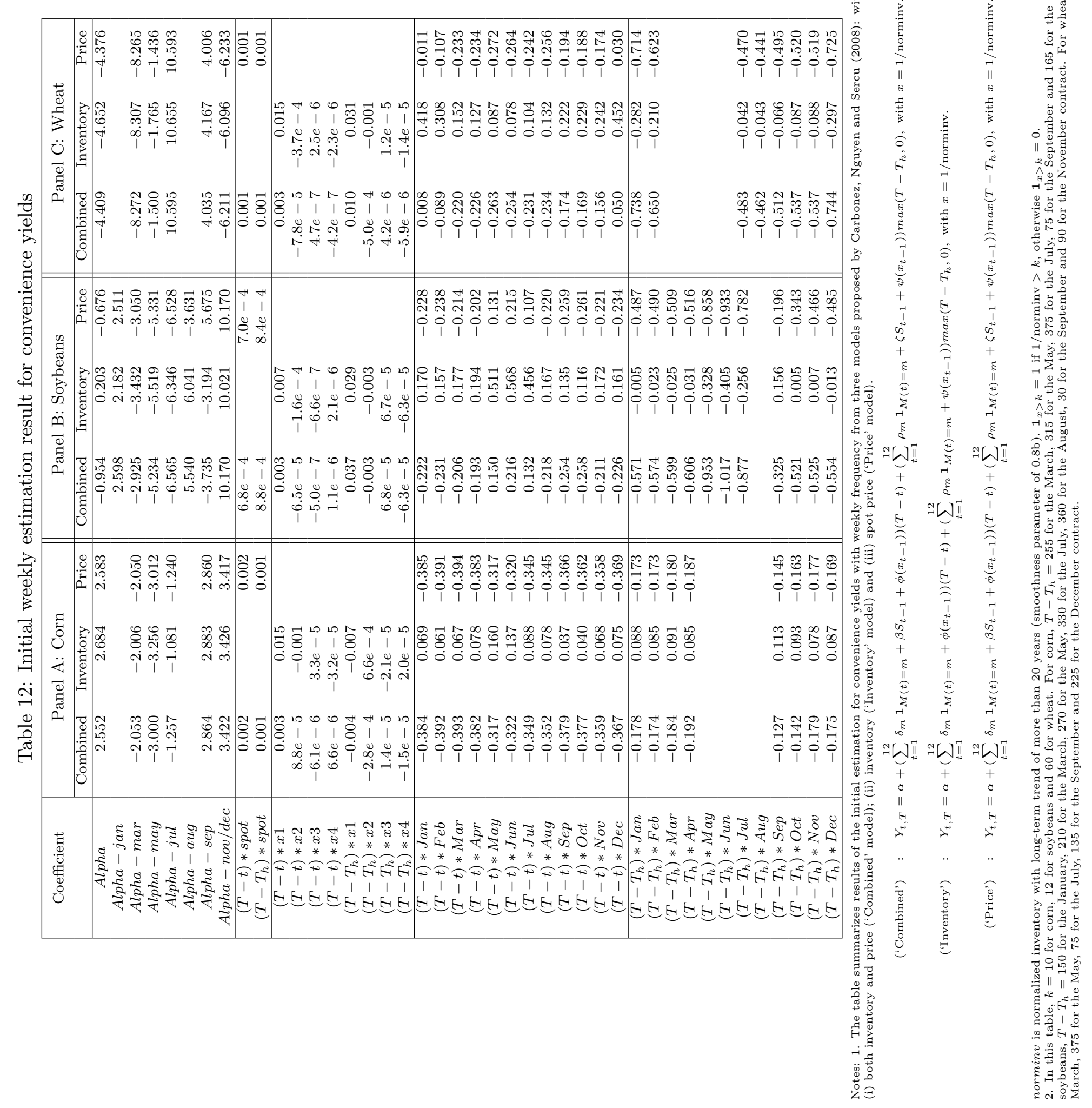

